\title{
Nanotheranosties
}

2017; 1(1): 38-58. doi: 10.7150/ntno.17694

Review

\section{Targeted Nanomaterials for Phototherapy}

\author{
Upendra Chitgupi*, Yiru Qin*, Jonathan F. Lovell ${ }^{\bowtie}$ \\ Department of Biomedical Engineering, University at Buffalo, State University of New York, Buffalo, New York, USA. \\ *equal contribution. \\ $\triangle$ Corresponding author: jflovell@buffalo.edu. \\ ( $)$ Ivyspring International Publisher. This is an open access article distributed under the terms of the Creative Commons Attribution (CC BY-NC) license \\ (https://creativecommons.org/licenses/by-nc/4.0/). See http://ivyspring.com/terms for full terms and conditions.
}

Received: 2016.09.24; Accepted: 2016.11.30; Published: 2017.01.01

\begin{abstract}
Phototherapies involve the irradiation of target tissues with light. To further enhance selectivity and potency, numerous molecularly targeted photosensitizers and photoactive nanoparticles have been developed. Active targeting typically involves harnessing the affinity between a ligand and a cell surface receptor for improved accumulation in the targeted tissue. Targeting ligands including peptides, proteins, aptamers and small molecules have been explored for phototherapy. In this review, recent examples of targeted nanomaterials used in phototherapy are summarized.
\end{abstract}

Key words: targeting, photodynamic therapy, photothermal therapy, photosensitizers, cancer.

\section{Introduction}

The use of light to treat diseases like vitiligo and psoriasis dates back to ancient times [1, 2]. Niels Ryberg Finsen used ultraviolet light for lupus treatment and was awarded a Nobel Prize in 1903 [3, 4]. Phototherapy has potential for treating many diseases such as gum diseases [5,6], cheilitis [7] and several types of cancer [8-14]. It is relatively safe and minimally invasive when used for superficial conditions. Photosensitizer-enhanced phototherapy can be broadly classified into two categories; photodynamic therapy (PDT) and photothermal therapy (PTT). These approaches use light of a fixed wavelength to activate administered photosensitive molecules to introduce therapeutic effects. Nanomaterials, which have excellent capability for theranostic approaches, hold good potential for phototherapy $[15,16]$. Phototherapy can be used as standalone treatment or can be combined with traditional chemotherapy to generate synergistic effects [17].

PDT requires three components: a light source, a photosensitizer (PS), and oxygen. When PS is irradiated by light of specific wavelength, it generates reactive oxygen species (ROS) that are cytotoxic to the surrounding environment. Upon irradiation, the PS absorbs a photon and is transformed to an excited state from its ground state. Then it undergoes intersystem crossing to a triplet state accompanied by loss of energy as heat, fluorescence emission, or other photophysical energy. In the process of returning to the ground state, the PS creates ROS. In type I reactions, the PS directly reacts with substrates to produce radicals, whereas in type II reactions, molecular oxygen interacts with the triplet state PS to create reactive singlet oxygen. Type II reactions are believed to be more relevant for PDT [18-20]. Singlet oxygen only affects the immediately surrounding environment where it was generated, usually within a $20 \mathrm{~nm}$ radius [21]. Thus, targeted delivery of a PS to the intended area holds potential to pinpoint the site of therapeutic efficacy.

PTT involves different mechanisms than PDT. Thermal homeostasis is crucial for optimal functioning of all biological activities. Contrast-enhanced PTT involves delivering a light-absorbing material to the region of interest and light-induced temperature elevation resulting in tissue ablation. Although the detailed interaction of the thermal effects on tissues and their surroundings are complex, nanomaterials-based PTT has been used to treat a variety of cancers in vitro and in vivo [22-24].

Typical PS used in phototherapy generally 
should not be cytotoxic in the absence of light irradiation. However, tumor selectivity of the photosensitive agent is limited and it may be practically difficult to irradiate only tumor cells since normal tissues may be adjacent to lesions. In order to improve selectivity and to potentially use lower doses to reduce dark or sunlight toxicity, various strategies can be employed. One strategy is to use PS that is selectively activated at tumor sites [25]. Alternatively, nanocarriers have been developed to selectively accumulate photosensitive agents in the region of interest. Passive targeting involves enhanced permeability and retention of nanoparticles in tumors $[26,27]$. Active targeting involves directing PS to target tissues via ligands which bind to surface receptors on the target cells.

This review intends to serve as a general overview of targeted phototherapy agents. We discuss common small molecule and nanoparticulate agents for both PDT and PTT. We describe various targeting mechanisms including passive targeting, physical targeting and active molecular targeting. Finally, within the realm of molecular targeting, we highlight examples of targeted phototherapy based on peptide ligands (e.g. RGD, epidermal growth factor (EGF) and Angiopep-2), protein ligands (e.g.antibodies and transferrin), aptamers and other ligands including small molecules (e.g. folate and carbohydrates).

\section{Phototherapy agents}

The selection of the phototherapy agent is essential for contrast-enhanced phototherapy. These agents should absorb light at a defined wavelength, preferably in near infrared region if improved light penetration is desired. They should not be overly cytotoxic to cells or trigger immune response without light irradiation. For some targeting approaches, they should rapidly clear from the blood and healthy tissues to ensure the targeted phototherapy agents have high contrast and minimal dark toxicity. In addition to the above mentioned properties, they should possess photostability which can result in better phototherapeutic capabilities.

\section{Photodynamic agents}

\section{Tetrapyrroles}

Tetrapyrrole-related molecules are a common group of PS used in PDT. Such molecules including heme, cytochromes and chlorophyll are found abundantly in nature and have excellent potential for imaging and therapeutic approaches [28-31]. Porphyrins, chlorins, phthalocyanines, and bacteriochlorins all belong to the tetrapyrrole family and have been investigated as PS for PDT. Several have been approved or are being clinically tested for PDT including but not limited to Photofrin, aminolevulinic acid -induced protoporphyrin IX, Foscan, Verteporfin, Monoaspartyl chlorin e6, 2-(1-hexyloxyethyl)-2-devinyl pyropheophorbide-a (HPPH), TOOKAD, LUZ11, and Liposomal ZnPc [32]. PS have been the subject of in-depth reviews [32, 33].

\section{Other photoactive dyes}

Many other photoactive dyes, small synthetic organic compounds, have been found to have photodynamic properties in either antimicrobial applications or anti-cancer applications. Common dyes that have been investigated for PDT include phenothiazinium salts (methylene blue and toluidine blue), rose Bengal, squaraines, borondipyrromethene, phenalenones, and indocyanine green (ICG) [32]. ICG, whose absorption peak is around $800 \mathrm{~nm}$, was evaluated as a suitable dye for PDT in melanoma cells in vitro [34]. Kester and colleagues successfully targeted ICG-loaded nanoparticles for PDT to leukemia in vivo beyond the solid tumors [35]. These nanoparticles enable deep light tissue penetration which improves PDT efficacy. CD117-ICG-loaded calcium phosphosilicate nanoparticles were able to specifically target leukemia stem cells and improve survival by $29 \%$ in leukemic mice. Another study investigated the PDT anti-biofilm efficacy of chitosan-conjugated rose bengal (CSRB) on Enterococcus faecalis (gram positive) and Pseudomonas aeruginosa (gram negative) [36]. Their results indicated that the CSRB irradiated at 540 $\mathrm{nm}$ has significant higher uptake and bacterial biofilm eliminating effect on gram-positive and gram-negative bacteria than both rose bengal and methylene blue. CSRB also displayed higher disruption of biofilm architecture on both bacteria.

\section{Natural compounds}

Some plant-extracted natural compounds have been found to be phototoxic. Therefore, studies examined the potential of these compounds as PS for PDT. It can be advantageous to use naturally existing compounds as PS since they tend to have fewer biocompatibility issues. Natural products, for example, hypericin (Hy) [37, 38], hypocrellin [39], riboflavin [40], and curcumin [41, 42] have been studied in PDT. The ח-electron systems in these molecules are responsible for the light absorption that leads to generation of singlet oxygen species upon excitation with visible light [43]. A natural product extracted from hypericum, Hy, was loaded in lipid nanocapsules to examine PDT efficacy in human cervical carcinoma cells [37]. The nanoparticle loaded with Hy possessed an increased solubility and 
improved production of singlet oxygen upon the irradiation at $580 \mathrm{~nm}$, leading to a marked decrease in cell viability.

\section{Inorganic nanoparticles}

Several inorganic nanoparticles also display potential for phototherapy approaches, including titanium dioxide [44], quantum dots [45, 46], upconversion nanoparticles (UCNPs) [47, 48], gold nanoparticles [49, 50], mesoporous silica nanoparticles [51, 52], and carbon nanomaterials (carbon nanotubes, graphene, and fullerenes). Some of these materials can alter the excitation wavelength used for the PS. UCNPs have found application in phototherapy owing to such distinctive light absorption and emission properties. After absorbing light of longer wavelengths, they can emit light in the visible region which could then be used to initiate PS activation. $\mathrm{TiO}_{2}$ has strong photodynamic activity but is limited by weak tissue penetration of ultraviolet (UV) light. In order to overcome the drawback, UCNPs (NaGdF4:Yb/Tm) was developed as folic acid (FA)-targeted NaGdF4:Yb/Tm@SiO ${ }_{2} \mathrm{TiO}_{2}$ nanocomposites. Since the UCNPs can convert near-infrared (NIR) light to UV or visible light, $\mathrm{TiO}_{2}$ was excited by NIR to achieve NIR-responsive PDT in vivo, with additional MRI capabilities [53]. Inorganic nanoparticles can enable higher-order multimodal imaging approaches, which could be beneficial for phototherapy planning [54].

\section{Photothermal agents}

\section{Metallic nanoparticles}

Some metallic nanoparticles produce heat when illuminated with light of appropriate wavelength and have been investigated for PTT. Optical properties and heat generation is influenced by the size and shape of inorganic nanoparticles [55]. The most commonly used PTT metallic nanoparticles, gold ones, have been used in various shapes, including nanoshells [56], nanostars [57], nanorods (GNRs) [58], and nanospheres [59]. Among these, GNRs have attracted substantial interest in PTT applications owing to their strong and tunable NIR light-to-heat conversion efficiencies and physico-chemical properties. For example, Berlin and colleagues loaded GNRs to tumor-tropic neural stem cells (NSCs) and examined PTT efficacy in breast cancer xenografts in mice in vivo [60]. Upon NIR irradiation, the GNR-NSCs enhanced tumor ablation and reduced tumor recurrence via PTT. Rare earth (RE) metals are another nanoparticle for PTT. RE doped nanocrystals have been investigated in bioimaging and phototherapy applications [61-64]. Hu's group constructed imaging guided photothermal nanoparticle using $\mathrm{NaYF}_{4}: \mathrm{Yb} / \mathrm{Er}$ core coated with polypyrrole (PPy) shell and validated its PTT effect in vivo [65]. The temperature of nanoparticle dispersion increased significantly upon irradiation at $915 \mathrm{~nm}$ and no obvious decrease was observed after the cooling-heating cycles. PTT efficacy was tested using mice bearing TC71 tumors with increased tumor temperature to $47.6{ }^{\circ} \mathrm{C}$ and induced severe cellular damage.

\section{Carbon-based nanoparticles}

Light-induced heating of carbon-containing materials also have numerous applications in PTT. Carbon based nanomaterials, especially carbon nanotubes, have interesting properties for imaging applications [66]. Carbon-based materials used in PTT include graphene, single-walled carbon nanotubes (SWCNTs), and multi-walled carbon nanotubes (MWCNTs). Carbon-based nanomaterials have also been used in phototherapy due to their property to transfer energy from one form to another. For example, Hahn and colleagues designed a nano graphene oxide (GO)-hyaluronic acid (HA) nanoparticle for melanoma skin cancer PTT treatment [67]. The HA-NGO solution heated up by NIR laser at $808 \mathrm{~nm}$ reached $40^{\circ} \mathrm{C}$ and completely ablated tumor tissues in the skin of mice with no recurrence. Another study compared the anticancer activity of carbon nanotubes and graphene nanoparticles via PTT [68]. Due to their high dispersivity, polyvinylpyrrolidone-coated graphene nanoparticles displayed better photothermal sensitivity than carbon nanotubes and induced increased cell death in human glioma U251 cells. The heating capacities of graphene nanoparticles and carbon nanotubes had also been predicted by the calculation taking into account the thermodynamic, geometrical, and optical properties. The theoretical calculation results were consistent with the experimental data indicating CNT tends to generate less heat than graphene nanoparticles. Carbon nanotubes have also been used to target primary tumor as well as lymph nodes leading to tumor remission [69].

\section{Quantum dots}

Quantum dots (QDs) have been widely used for fluorescence imaging. Owing to the quantum confinement effect, QDs exhibit unique optical properties. Heat can be delivered via either indirect band gap semiconductor like Ge-QDs or direct band gap semiconductors, such as CdS, CdSe, PbSe, InP, and CdTe [70]. $\mathrm{Ag}_{2} \mathrm{~S}$ QD conjugated with Apt43 aptamer was reported by Gao and colleagues [71]. The Apt43- $\mathrm{Ag}_{2} \mathrm{~S}$ QDs exhibited strong absorption in NIR region and high photothermal conversion efficiency. 
The QDs were able to selectively kill targeted MCF-7 cells and ablate tumors in nude mice effectively via PTT. Others developed a multifunctional tungsten sulfide $\left(W_{2}\right)$ QDs for dual-modal image-guided photothermal/radiotherapy therapy (PTT/RT) [72]. The $W_{2}$ QDs exhibited PTT/RT synergistic effect upon the irradiation at $808 \mathrm{~nm}$ both in vitro using $4 \mathrm{~T} 1$ cells and in vivo using BEL-7402 tumor-bearing mice. Moreover, the $\mathrm{WS}_{2}$ QDs possessed X-ray computed tomography (CT)/ photoacoustic (PA) signal. Therefore, QDs can serve as CT/PA imaging agents for precise positioning of the tumor and thus enhancing the PTT efficacy further. QDs have also been used to induce damage in bacteria. Courtney et al. developed QDs capable of targeting bacteria selectively which was verified in a co-culture of E. coli and HEK 293T cells [73].

\section{Organic nanoparticles}

Clinical applications of inorganic nanoparticles have been limited potentially due in part to biocompatibility concerns. Inorganic materials are difficult to eliminate from the body due to their low biodegradability and might give rise to long-term toxicity. Organic nanoparticles might be able to provide better targeting along with decreased toxicity. Several groups have used organic nanoparticles with ICG [74-76] or porphyrin-phospholipids [77-85] to demonstrate advantages of organic nanoparticles. For example, a novel porphyrin based nanoparticle, porphysome based nanoplatform (FRETysomes), designed by Zheng's group exhibited PTT effect based on Förster resonance energy transfer [77]. FRETysomes displayed high accumulation, strong photothermal heating, and light-induced thermal toxicity to tumors in nude mice with $\mathrm{KB}$ xenografts.

\section{Dual PDT and PTT agents}

Therapeutic effects of phototherapy can be enhanced with the use of both PTT and PDT which would provide synergistic effects. Usually, the combination therapy needs to incorporate two PS, which makes the carrier less efficient and also requires multi-wavelength lasers to activate both PS simultaneously [86, 87]. However, some PSs have been investigated for their dual-function for PDT and PTT. Carbon dots have attracted attention due to their applications in bioimaging [88] and phototherapy [89-91]. The carbon dots synthesized by Wang and colleagues exhibited dual PDT and PTT effects upon irradiation with $635 \mathrm{~nm}$ laser. These carbon dots exhibited high photothermal conversion efficacy of $36.2 \%$ and a moderate singlet oxygen species generating efficacy of $27 \%$ [89]. ICG-based liposomes were developed with synergistic PTT/PDT capabilities for breast cancer targeting [92]. iRGD peptide conjugated liposomes loaded with ICG increased the tumor temperature and generation of ${ }^{1} \mathrm{O}_{2}$ resulting in significant inhibition of tumor size in 4T1 breast cancer-bearing mice. The iRGD-ICG-liposome exhibited dual therapeutic potential via PDT and PTT. In another example, a unique gold nanoechinus with favorable optical properties in the NIR region was reported [93]. These gold nanoparticles display PDT/PTT capability in NIR window-I as well as window-II. Dual PDT/PTT efficacy of nanoechinus was verified in melanoma tumor-implanted mice. An increase in ROS generation, temperature rise, and expression of heat shock protein (HSP70) confirmed the synergistic therapeutic potential of gold nanoechinus.

\section{Targeting mechanisms}

In order to achieve a desirable therapeutic effect, there are two basic principles associated with the design of the nanoparticles. First, they should be able to reach the intended sites with minimal activity or volume loss during their circulation in the body. Secondly, nanoparticles should be able to selectively target and kill the intended cells without affecting the surrounding healthy tissue, ideally, with a controlled release mechanism. Nanoparticles seem to have the potential to meet these criteria based on a variety of targeting techniques. Passive targeting and active receptor targeting are two of the most commonly employed targeting methods [94]. Physical forces such as magnetic or electric fields, light, or heat may also contribute to targeting and activating of nanoparticles. In the following section, passive targeting, magnetic targeting, light-induced targeting, heat-induced targeting, and active ligand-targeting will be discussed.

\section{Passive targeting}

By modifying the size and surface characteristics, nanoparticles can be entrapped and accumulate in tumors, commonly referred to as passive targeting [95]. This is based on morphological and physiological differences between tumor and normal tissues. Two major factors that affect passive targeting are tumor microenvironment and enhanced permeability and retention (EPR). Tumor cells have high anaerobic metabolic rate and upregulation of glycolysis leading to an acidic microenvironment [96]. Tumor cells also utilize some special enzymes like matrix metalloproteinases to achieve metastasis. Moreover, angiogenesis, growth of new blood vessels, and compromised lymphatic drainage resulting in higher interstitial pressure at the center of tumors than the periphery are some of the unique 
characteristics of tumor tissues. These features allow the nanoparticles to selectively accumulate and retain in tumor interstitium, leading to a phenomenon called EPR effect. The size of the nanoparticles should be between $10 \mathrm{~nm}$ and $200 \mathrm{~nm}$ which would ensure it is small enough to escape the macrophages capture in reticulo-endothelial system and large enough to avoid the leakage into blood capillaries $[97,98]$. Some other innate characteristics of nanoparticles such as charge [99] and PEGylation [100, 101] are also important for passive targeting. Liposomes with positive charge can bind to tumor endothelial cells by the electrostatic interactions between anionic phospholipids on cells and cationic liposomes [102, 103]. PEGylation, the modification of nanoparticles or other molecules by linking or coating polyethylene glycol (PEG) chains, can increases the half-life of the nanoparticles. Studies have shown that PEG-modified liposomes and micelles exhibit an enhanced passive targeting effect in tumor and slower clearance rate from bloodstream in tumor-bearing mice leading to efficient PDT activity [100, 104]. Although EPR-based passive targeting is the basic targeting mechanism and has been proven to be effective in vivo, it still possesses several limitations. Some tumors, especially at early stages, may not display the EPR effect. Moreover, even in a single tumor, blood vessel permeability is not uniform throughout so the EPR effect-based nanoparticle may show limited efficacy [105]. To overcome these limitations, active targeting and physical force activatable targeting mechanisms have been developed to achieve more efficient targeting.

\section{Physical targeting}

\section{Magnetic targeting}

Magnetic targeting utilizes a magnetic field to specifically direct theranostic agents to the intended sites and improve the effectiveness of the phototherapy. Magnetic nanoparticles carrying the PS can be attracted by the magnetic field during the bloodstream circulation and retained in the external magnetic field applied site. Magnetic field-guided PDT [106, 107] and PTT [108-113] have been studied successfully by various groups. Superparamagnetic $\mathrm{Fe}_{3} \mathrm{O}_{4}$ has been used with Prussian blue dye to create nanoparticles for magnetically-targeted PTT [112]. PEG coated $\mathrm{MoS}_{2} / \mathrm{Fe}_{3} \mathrm{O}_{4}$ nanoparticles have been shown to be magnetically targeted for internalization in cancer cells and exhibit in vivo PTT efficacy in BALB/C nude mice bearing pancreatic tumors (PANC-1) [110]. Some novel contrast agent nanoparticle used in phototherapy include $\mathrm{Gd}(3+)$-ion $[53,114,115], \mathrm{Fe}_{5} \mathrm{C}_{2}$ [116], $\mathrm{FeS}$ [117], and nanoscale metal-organic particles (NMOP) [118]. For example, $\mathrm{NaGdF}_{4}$ nanoparticles were used as a $\mathrm{T}_{1}$-weighted contrast agent for MRI and can convert NIR light into visible or UV light when doped with lanthanides such as $\mathrm{Yb} / \mathrm{Tm}$ or $\mathrm{Yb} / \mathrm{Er}$. MRI guided tests were performed in MCF-7 and HeLa cells in vitro and MCF-7 tumor-bearing nude mice in vivo showing good $\mathrm{T}_{1}$-weighted MRI performance [53]. A new type of NMOP synthesized by self-assembling IR825 bridging ligands and $\mathrm{Mn}^{2+}$ ions exhibited strong $\mathrm{MR}$ contrast. After coating with polydopamine (PDA) and PEG, these Mn-IR825@PDA-PEG NMOPs displayed efficient tumor accumulation and photothermal ablation in $4 \mathrm{~T} 1$ murine breast cancer-bearing mice [118].

\section{Heat-induced targeting}

Heat-induced targeting is based on accumulation of thermosensitive nanoparticles or drug at the site of tumor with thermal treatment to the intended site. Anti-cancer drugs loaded into the nanoparticles can be released at or adjacent to the heated tumor site, resulting in the targeted accumulation of drugs. Site-specific drug release using thermosensitive liposomes in response to hyperthermia has been examined [119]. In another study involving thermal targeting, a polypeptide drug delivery system was developed that displays nanoparticle-to-aggregate transition at hyperthermia condition and shows preferential accumulation in heated tumors. The structure of this nanoparticle consisted of a thermally responsive elastin-like polypeptide and a cysteine-rich peptide tail for drug loading. When the tumor was heated to $42{ }^{\circ} \mathrm{C}$, the polypeptide nanoparticles transformed to micrometer-sized aggregates, therefore, could adhere to the tumor vasculature and achieve heat-induced targeting activity [120].

\section{Light-induced targeting}

Similar to heat-induced targeting, light-induced targeting is not based directly on the light-guided accumulation of nanoparticle, but achieved by the light-activated functionality of the nanoparticle. For example, the nanoparticle can release the drug, convert energy to heat or fluorescence, or generate singlet oxygen species in the accumulated sites when irradiated with light [121-123]. Upon irradiation of light at the intended tissues or cells, the nanoparticles can be activated with PDT, PTT, or dual PDT/PTT. More interestingly, light energy in this mechanism can be not only be from an external light source, but can also be generated from internal bioluminescence (BL) $[45,124]$. Recently, luciferase (RLuc8)-Quantum dots (QD-655) nanoparticles (Luc-QD) were shown to work with the PS Chlorin e6 (Ce6) for BL-PDT. When luciferin coelenterazine, Luc-QD, and Ce6 were 
injected intratumorally, the BL generated by nanoparticles was transferred to nearby Ce6 molecules activating them leading to tumor cell death via PDT. This finding could overcome the limitation of the poor external light penetration in tissues and provide a novel paradigm for light-activated therapy [125]. Light-induced drug delivery systems for cancer treatment have been also investigated by several researchers. For example, Urtti's group developed a series of thermal-sensitive gold nanoparticle liposomes as drug delivery carriers. When light was introduced after administration, the gold nanorods (GNRs) absorbed the light energy and converted it to heat, which rendered the thermal-sensitive liposomes leaky leading to release of the drug at the light-irradiated sites [126]. Light-triggered liposomes have been developed to release a variety of drugs including irinotecan, doxorubicin and mitoxantrone [127-130].

\section{Active targeting}

A constant need for nutrients for cancer cells to proliferate gives rise to overexpression of specific receptors. Targeting receptors within the tumor with nanomaterials possessing affinity towards those overexpressed receptors is active targeting. In comparison with passive targeting, active targeting stands out due to its potential for improved tumor targeting and accumulation usually via receptor mediated endocytosis. Figure 1 gives a summary of common targeting ligands along with commonly used nanoparticles in phototherapy.

Based on the affinity of the ligands to specific receptors expressed on the surface of the cell, various ligands like antibodies, peptides, nucleic acids, proteins have been employed for active targeting (Table 1). Although PEGylation increases the half-life of the nanoparticle, for active targeting methods, amount of PEG has to be carefully chosen since excess PEG might mask the smaller ligands thus hindering the ligands from interacting with the receptor. The targeting ligand can be placed at the terminus of the PEG group to circumvent this. With the use of comparatively bigger ligands like proteins, hindrance originating from PEG is generally mitigated and half-life of the carrier is enhanced [131]. Efficacy of the system also depends on the number of ligands present on the surface of the nanoparticle since lower number of ligands might decrease receptor-ligand interaction and excess free ligands might lead to binding inhibition. A recent study on effect of carrier to ligand ratio on uptake efficiency demonstrated nanoparticle uptake to be directly related to the number of ligands on the surface [132]. Nanoparticles with higher transferrin on the surface enhanced the binding which could be attributed to enhanced receptor-ligand

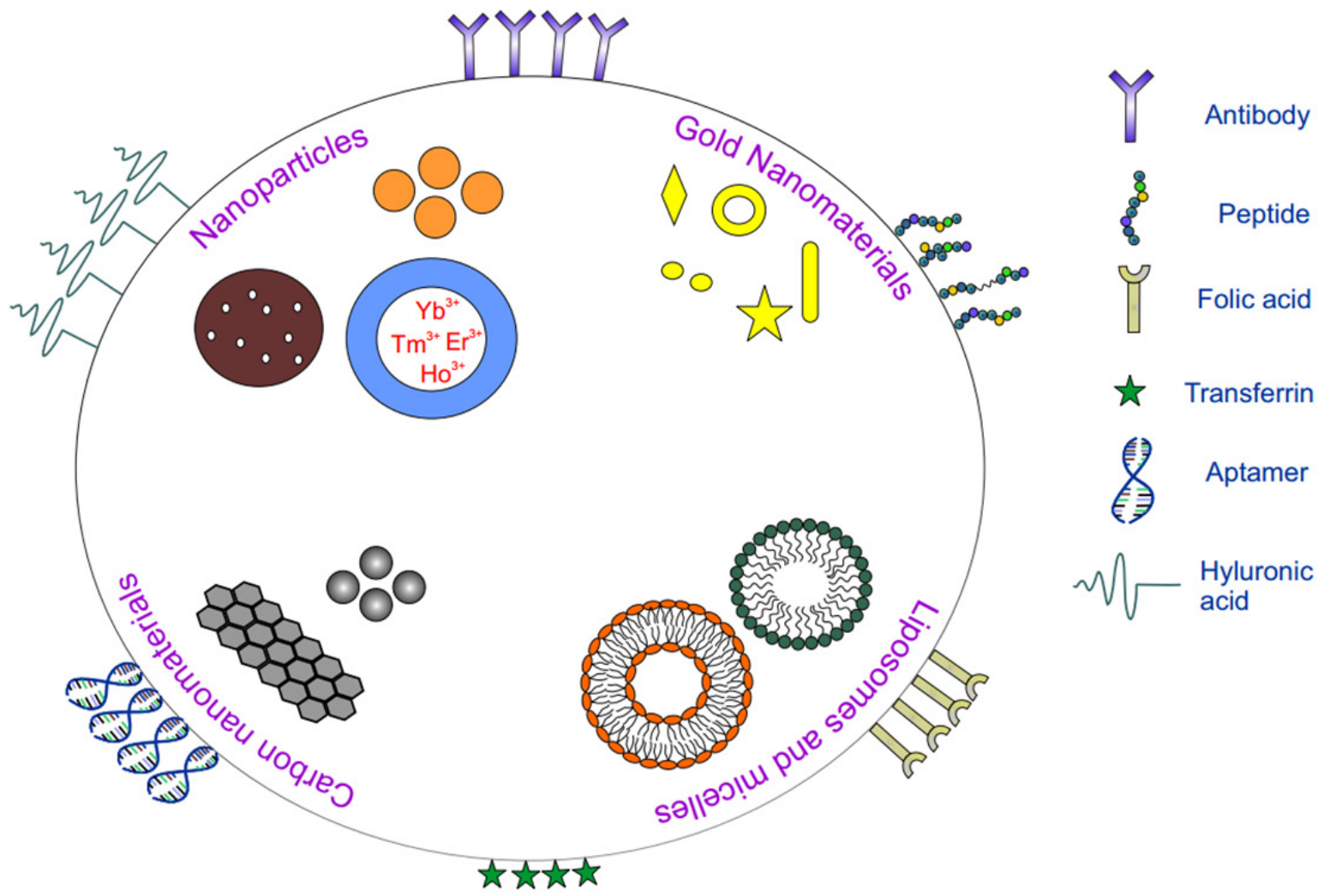

Figure 1: Schematic showing various nanoparticles and ligands used in active targeting for phototherapy. 
interactions leading to more efficient active targeted delivery systems. In general, targeting agents can be broadly divided into the following categories: peptides and proteins (antibodies), nucleic acids (aptamers), and other receptor ligands (vitamins and carbohydrates).

\section{Peptides}

Specific short amino acid sequences can bind to receptors within tumors. Such peptides carry advantages over other larger molecules like antibodies, including reduced cost, ease of scale up and clinical production, and improved targeting efficacy. Further, peptides also offer targeting advantages like improved tissue diffusion and high stability over time. Since peptides are stable over long periods of time, modifications are relatively easy [144]. Additionally, short sequence peptides, which are frequently employed in targeting, are small in size and thus do not influence carrier material properties [145-147]. Peptide conjugated drug/PS carrier can result in decreased renal filtration due to their increased size. Since peptides are biocompatible, risks associated with immunogenicity are low. On the other hand, with the use of peptides for targeting there is risk of enzymatic degradation leading to inefficient targeting systems in vivo. Also, if the peptide has poor affinity for the receptor, nonspecific targeting and uptake is possible. Peptides have also been employed as passive components to provide desirable properties to targeting molecules [148]. Knowing the binding domains of cell surface receptors, peptide sequences can be modeled to bind to their targets. For example, vitronectin, an essential glycoprotein for cell spreading and proliferation, is known to bind to specific integrins [149].

\section{RGD}

Since tumor growth involves angiogenesis, this has served as one of the traits to identify growing tumors and has hence served as a target. Antiangiogenic targeting has attracted interest due to their potential to target and inhibit angiogenesis. One commonly used targeting method employs a tripeptide sequence, RGD (arginine-glycine-aspartic acid) to target $\alpha_{v} \beta_{3}$ integrin. $\alpha_{v} \beta_{3}$ integrins are glycoproteins which belong to the broad family of integrin cell adhesion molecules; overexpression of these integrins on the surface of endothelial cells serves as a target for receptor-ligand binding.

Table 1: Examples of targeted nanomaterials for phototherapy.

\begin{tabular}{|c|c|c|c|c|c|c|}
\hline Targeting Ligand & Carrier & Therapy & Receptor & In vivo model & Results & Ref \\
\hline cRGD peptide & GNR@Mesoporous silica & $\begin{array}{l}\text { PTT } \\
\text { Chemo }\end{array}$ & $\alpha_{v} \beta_{3}$ & A549 & Synergistic treatment & [133] \\
\hline RGD peptide & GNR/PAMAM dendrimer & PTT & $\alpha_{v} \beta_{3}$ & A 375 & Tumor reductions or cures & [134] \\
\hline EGF peptide & GNP & PDT & EGFR & 9L.E29 & $\begin{array}{l}\text { Targeted vs non-targeted results better } \\
\text { at lower dose }\end{array}$ & [135] \\
\hline Angiopep-2 peptide & PLGA@GNP & PTT Chemo & $\alpha_{v} \beta_{3}$ & U87MG & Synergistic treatment & [155] \\
\hline TCP-1, HA1 peptide & Hydrogel - GNR, GNSh & $\begin{array}{l}\text { PDT Chemo } \\
\text { Gene }\end{array}$ & Membrane fusion & CRC model & Synergistic treatment, tumor cures & [163] \\
\hline cRGD & PS-Peptide conjugate & PDT & $\alpha_{v} \beta_{3}$ & CaNT & Necrosis observed & [136] \\
\hline APRPG & Liposomes & PDT & VEGF & Meth A Sarcoma & Tumor growth inhibition & [161] \\
\hline CREKA peptide & MWCNT & PTT & Fibrin & A549 & Extensive coagulative necrosis & [193] \\
\hline Nanobody 7D12 & PS-nanobody conjugate & PDT & EGFR & OSC-19 & Enhanced necrosis & [137] \\
\hline Folic acid & Mesoporous silica, UCNP & PDT & FR & B16F0 & Tumor growth inhibition & [47] \\
\hline Folic acid & UCNP & PDT & FR & Hepa1-6 & Tumor growth inhibition & [138] \\
\hline Folic acid & Porphysome & PDT & FR & $\mathrm{KB}$ & $\begin{array}{l}\text { Reduced tumor growth, increased } \\
\text { survival }\end{array}$ & [139] \\
\hline Folic acid & Silica modified GNR & PTT & FR & MGC803 & $\begin{array}{l}\text { Successful targeting, PTT studies in } \\
\text { progress }\end{array}$ & [204] \\
\hline Folic acid & Nanodiamond & PTT & FR & $\mathrm{KB}$ & Tumor size significantly reduced & [206] \\
\hline LDL & LDL & PDT & LDLR & HepG2 & Tumor growth inhibition & [184] \\
\hline Hematoporphyrin targeting & BSA & PDT & LDLR & HepG2 & Tumor growth inhibition, necrosis & [192] \\
\hline Transferrin & $\mathrm{TiO}_{2}$ & PDT & TfR & HT1080, A549 & $\begin{array}{l}\text { Eight fold tumor growth inhibition, two } \\
\text { fold increase in survival }\end{array}$ & [140] \\
\hline Transferrin & Tf-IR780 NP & PDT PTT & TfR & CT26 & $\begin{array}{l}\text { Accumulation in tumor, tumor growth } \\
\text { inhibition }\end{array}$ & [141] \\
\hline Transferrin & Liposome & PDT & TfR & AY-27 & Accumulation of liposomes in tumor & [181] \\
\hline AS1411 aptamer & Aptamer-PS Conjugate & PDT & Nucleolin & MCF7 (in vitro) & Reduced cell viability & [142] \\
\hline Hyaluronic acid & Hyaluronic acid NP & PDT & CD44 & HT29 & $\begin{array}{l}\text { Accumulation in tumor, tumor growth } \\
\text { inhibition }\end{array}$ & [143] \\
\hline Hyaluronic acid & Hyaluronic acid NP & PDT & CD44 & A549 & Tumor growth inhibition & [219] \\
\hline
\end{tabular}


Since $\alpha_{v} \beta_{3}$ integrin has proven to be a promising target, many groups have successfully targeted integrins for PDT and PTT. RGD-modified ferritin nanocarriers have been developed for PDT-induced enhanced tumor permeability [150]. Mesoporous silica nanoparticles, which allow for simple and easy methods to load phototherapeutic agents into the core, have been used to target angiogenic regions of the tumor [151]. Various facile synthesis methods have been established to manipulate the size of mesoporous silica nanoparticles based on their application [152]. PS loaded mesoporous silica nanoparticles conjugated to a fluorophore and RGD-peptide were used to establish $a_{v} \beta_{3}-R G D$ binding and to demonstrate PDT efficacy [151]. $\alpha_{v} \beta_{3}$ overexpressing cells (U87) were used to demonstrate selective binding and cells lacking $\alpha_{v} \beta_{3}$ expression (MCF7) were used as negative control. Internalization of nanoparticles mediated by $a_{v} \beta_{3}$ integrin was confirmed by blocking experiments. Targeted cells, when exposed to laser, showed a decrease in the cell viability. Another group demonstrated chemophototherapy by loading doxorubicin into mesoporous silica nanoparticles encapsulated with GNRs [133]. Receptor mediated targeting was facilitated by conjugating RGD peptide to nanoparticles. Mice induced with tumors overexpressing $\alpha_{v} \beta_{3}$ integrin showed an increase in the accumulation of nanoparticles in the region of tumor. Besides efficient targeting, these nanoparticles also showed high cytotoxicity when irradiated with laser. The toxicity in the tumor cells was attributed to synergistic effects originating from GNRs and doxorubicin contributing to PTT and chemotherapy respectively. These results collectively demonstrate the efficacy of mesoporous silica nanoparticles as phototherapeutic carriers. PS conjugated peptides have also found success in targeting tumor tissues $[136,222]$. Protoporphyrin IX conjugated cyclic RGD peptides injected into tumor bearing mice accumulated in the tumor, showing successful targeting. Further, laser irradiation induced tumor necrosis demonstrating the PDT capability of PS-peptide conjugates.

Liposomes have also been used in active targeting and phototherapy. Yan et. al. used ICG loaded RGD conjugated liposomes to target angiogenesis in the tumor. In vivo studies were carried out on 4T1 tumor bearing mice. Fluorescence imaging of mice exhibited a clear demarcation between tumor and healthy tissue as the liposomes accumulated in the region of tumor (Figure 2A). Quantitative in vivo data obtained from ICG signal intensity in the organs confirmed ICG-RGD-liposomes to be the most effective with highest signal intensity in the region of tumor (Figure 2B). In vivo PTT with ICG-liposomes led to a rise in temperature to $51.7^{\circ} \mathrm{C}$ and also showed close to 4 fold increase in ROS generation (Figure 2C and 2D). Studies monitoring tumor growth showed complete regression in mice treated with ICG-RGD-liposomes (Figure 2E). Survival studies corroborated with in vivo PTT results showing ICG-RGD-liposomes have good PDT and PTT capabilities (Figure 2F).

UCNPs were synthesized with $\mathrm{NaYF}_{4}: \mathrm{Yb} / \mathrm{Er}$, coated with chitosan and conjugated to cyclic-RGD and pyropheophorbide to demonstrate targeting and therapeutic efficacy [153]. UCNPs conjugated to RGD bound to U87 cells, whereas they did not exhibit significant binding with MCF-7 cells. Peptide conjugated nanoparticles proved to be cytotoxic to U87 cells showing a marked reduction in cell viability whereas no cytotoxicity was shown on MCF-7 cells. Dendrimer coated GNRs have also been reported in the literature which could target $\alpha_{v} \beta_{3}$ integrins selectively by conjugating RGD peptide on the surface [134]. Due to the facile synthesis methods that gold nanomaterials offer, they have been extensively used in phototherapy applications. However, these syntheses techniques often use CTAB coated gold nanoparticles which are toxic to cells [154]. Li and group have investigated modified GNR by coating the GNRs with dendrimer like polyamidoamine (PAMAM) to replace CTAB in order to reduce the toxicity associated with GNRs. RGD conjugated Dendrimer-GNR not only displayed reduced toxicity but were also able to target melanoma A375 cells in vivo. Although passive targeting with dendrimer-GNR showed GNR accumulation in the region of tumor, it did not show significant tumor reduction when exposed to laser. In contrast, with a short laser treatment at $24 \mathrm{~W} / \mathrm{cm}^{2}$ tumor growth slowed down in the mice pretreated with RGD-dendrimer-GNR and tumor shrunk within 3 weeks. Although RGD-dendrimer-GNR is a promising platform, further studies on toxicities associated with GNRs are warranted.

\section{Epithelial growth factor (EGF)}

In order to maintain fast-growing metabolism, tumor epithelial cells often overexpress receptors for nutrition and growth factors. EGF, a $6 \mathrm{kDa}$ small protein, stimulates the growth of epidermal and epithelial cells and has been proven to be an effective targeting moiety to treat several types of cancer overexpressing EGF receptors (EGFR). For example, Meyers and colleagues investigated the efficiency of EGF-peptide conjugated gold nanoparticles to deliver PS for PDT [135]. PEG coating on gold nanoparticles provided easy functionalization along with increased 
half-life. Peptide-conjugated nanoparticles containing PS displayed 35 folds higher uptake efficiency in 9L.E29 cells. In a few hours from injection, nanoparticles both with and without the peptide were seen to accumulate in the region of tumor. However, $24 \mathrm{~h}$ post injection results were different with only peptide bound nanoparticles accumulating in the region of tumor. Tumor tissue analysis revealed that EGF $_{\text {pep }}$ conjugated nanoparticles delivered 3.3 folds more Pc 4 compared to peptide-free nanoparticles.

Angiopep-2 and other peptides

The blood brain barrier (BBB) is a tight junction which blocks the penetration of drugs being delivered. Although many drugs have been designed for brain related diseases, the presence of the BBB has failed to turn them into successful therapeutics. Angiopep-2, a 19 amino acid peptide with sequence TFFYGGSRGKRNNFKTEEY, has been used as a specific ligand to cross the $\mathrm{BBB}$ and to target glial cells. A core-shell nanoparticles made up of PLGA-Gold and decorated with Angiopep-2 peptide capable of targeting the brain glioma has been developed by Zhang and colleagues [155]. Docetaxel-loaded core-shell nanoparticles showed improved targeting and tumors shrunk post PTT, confirming their efficiency.
A
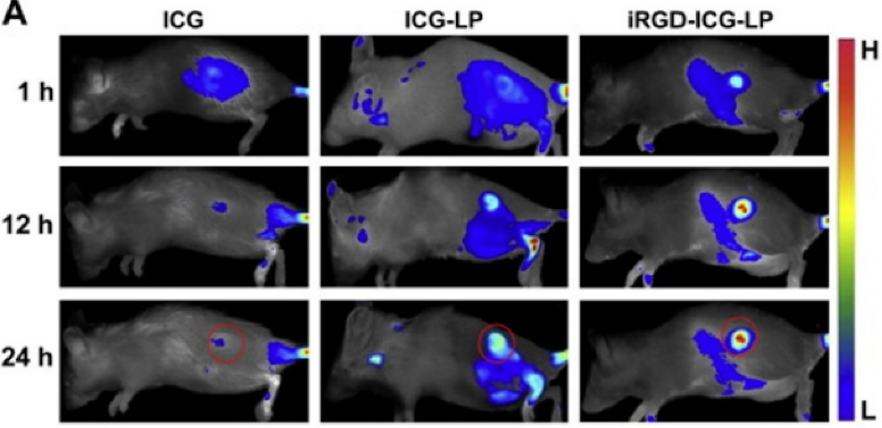

C

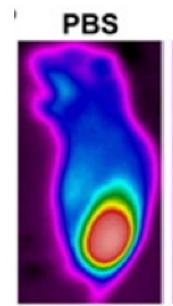

$41.4^{\circ} \mathrm{C}$
ICG

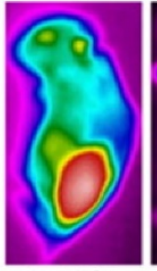

$41.8{ }^{\circ} \mathrm{C}$

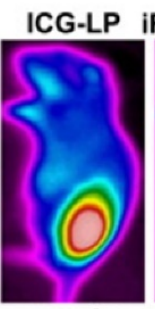

$47.6{ }^{\circ} \mathrm{C}$

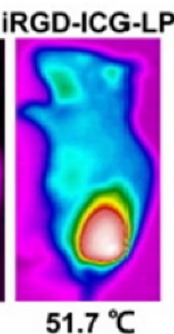

$55^{\circ} \mathrm{C}$

$\mathbf{E}$

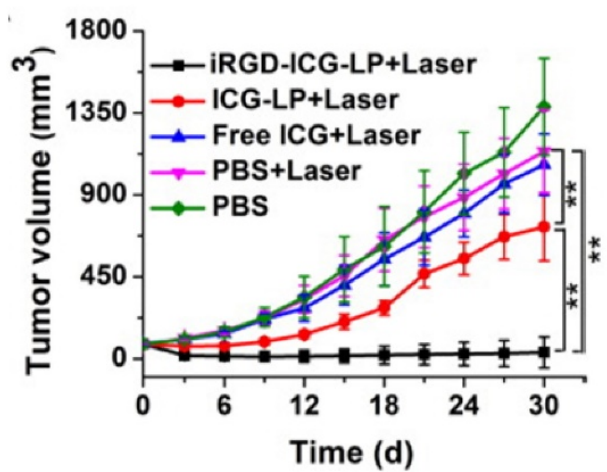

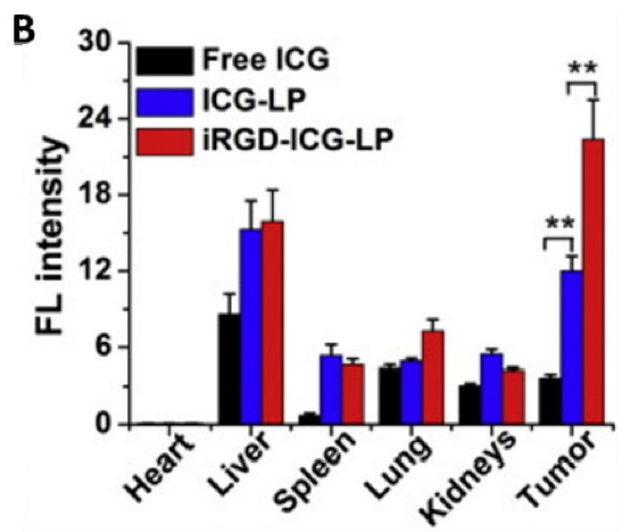

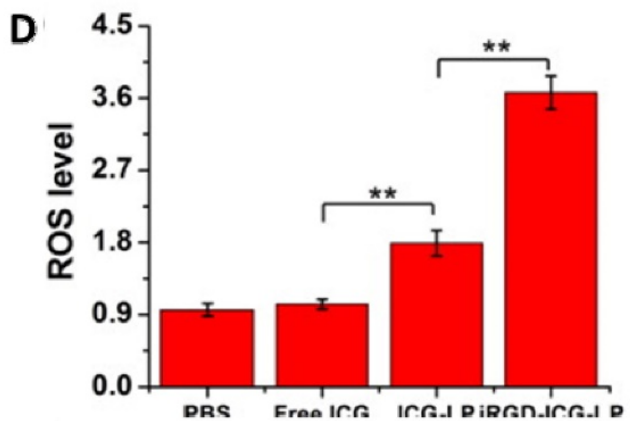

$\mathbf{F}$

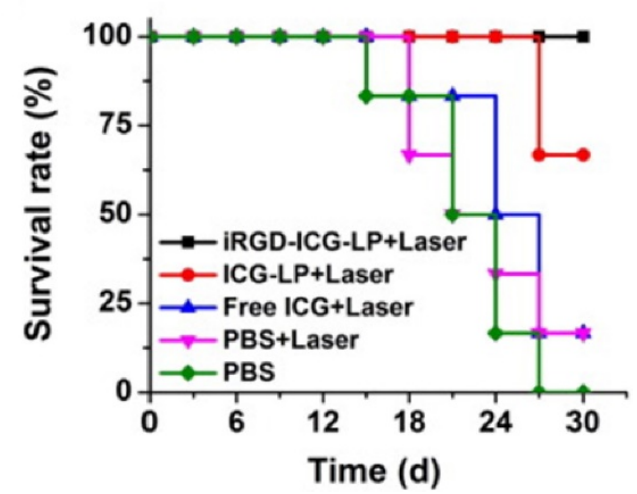

Figure 2: (a) Fluorescence imaging of 4T1 tumor bearing mice injected with ICG, ICG-liposomes, and iRGD-ICG-liposomes. (b) Ex vivo quantification of 4T1 tumor bearing mice injected with liposomes. (c) Photothermal efficiency of liposomes in vivo. (d) Release of ROS in the region of tumor post PDT treatment. (e) Tumor volume in treated and untreated mice with respect to time. (f) Survival data of tumor bearing mice treated with laser. Copyright Elsevier, 2016. Reproduced with permission from reference [92]. 
Cell penetrating peptides such as polyarginines have been shown to promote cellular uptake and penetration of nanoparticles [156, 157]. One such study involved in vitro delivery of heptaarginine $\left(\mathrm{R}_{7}\right)$ conjugated to a PS [158]. Peptide-PS conjugates were uptaken by MDA-MB-468 cells at a rate seven folds higher compared to PS alone. PDT results corroborated with in vitro uptake results showing higher cell death in peptide-PS conjugates compared to free Ce6. A transferrin specific peptide, T7 (sequence: HAIYPRH), has been shown to target transferrin overexpressing cells successfully [159]. A PS light-up probe was developed for the peptide to monitor the binding to cells in real time. Peptide conjugated light probe was able to successfully target and destroy MDA-MB-231 cells in vitro.

Another peptide which belongs to the cell penetrating peptides (CPPs) family has been employed for delivery of nanoparticles via peptide conjugation. TAT peptide, which belongs to the HIV binding domain protein, is known to deliver the cargo into the cell due to its cell penetrating property. Yuan et. al, demonstrated TAT peptide conjugated gold nanostars (NS) capable of higher uptake efficiency [160]. PEG conjugated NS-TAT exhibited enhanced uptake in BT549 breast cancer cells which confirmed the improved penetrating properties of TAT peptide. PEGylation had an interesting effect on gold nanostars; inclusion of PEG before peptide conjugation resulted in uniform nanostars whereas PEGylation post peptide conjugation resulted in rapid aggregation. With a laser power of only $0.2 \mathrm{~W} / \mathrm{cm}^{2}$, PTT was successfully demonstrated. Considerable cell death is induced post PTT demonstrating improved PTT effects at sub maximum permissible exposure laser power. Other groups have shown peptides like APRPG and apamin to target angiogenic regions of tumor $[161,223]$. Use of APRPG-liposomes resulted in a 4-fold increase in the delivery of PS. Polyacrylic acid coated gold nanomaterials have also been employed in peptide based delivery of therapeutics [162]. Although, the efficacy of polyacrylic acid coated nanoparticles after successful internalization remains to be seen.

Hydrogel based nanoparticle delivery for colon caricinoma has been developed based on peptide targeting [163]. GNRs and spheres conjugated to TCP-1 and HA-1 peptide were loaded with drug and implanted in mice as hydrogels. Irradiation with laser resulted in tumor ablation as a result of PTT. Complete survival was observed for 170 days, as a result of three therapies, chemo, photo, and gene therapy. In another study, dendrimers were used as a platform to conjugate tetrakis hydroxyphenyl porphyrins with HER2-targeting peptides [164].

\section{Proteins}

Another strategy to selectively target tumors involves the use of proteins to target receptors and antigens overexpressed on targeting cells.

\section{Antibodies}

High affinity between the antigen present on the surface of the cells and the antibody forms the basis of antibody based targeting. The use of antibody to target tumor antigen is frequently employed in targeted drug delivery. The application of antibody or antibody fragment conjugated with PS to achieve PDT is sometimes referred to as photoimmunotherapy [165]. The use of antibodies for PS delivery has been demonstrated in numerous studies [165-168]. Optimized results with improved targeting can be achieved by varying the number of antibodies per carrier molecule [169].

Some types of tumors can overexpress HER2 such as ovarian and breast cancer [170]. Van de Broek et al. used antibody targeting approach to target anti-HER2 antibodies conjugated gold nanoparticles to tumor tissue [171]. Antibody-PS conjugates showed high specificity by binding to HER2 overexpressing SKOV3 cells but not to $\mathrm{CHO}$ cells (HER2 antigen negative cell line). Subsequent experiments involving in vitro PTT demonstrated PTT efficacy leading to cell death due to the increase in temperature by $10{ }^{\circ} \mathrm{C}$. Further, an increase of $20{ }^{\circ} \mathrm{C}$ was observed when treated with higher concentration of nanoparticles displaying dose dependent efficacy.

In another approach, his-tagged nanobodies were used to prevent EGF interaction with its corresponding receptor by binding to domain III of the EGFR. These nanobodies were used as carriers to deliver PS (IRDye700DX) to the head and neck tumor region with high specificity [137]. Cells expressing varying levels of EGFR were employed to test the binding in vitro and a co-culture experiment was set up to demonstrate the specificity. In vitro experiments showed higher binding with antigen presenting cells and PTT on co-culture showed no toxicity to HeLa cells with intermediate EGFR expression, whereas the cell viability of OSCs (oral squamous cell carcinoma cell line overexpressing EGFR) reduced. Mice induced with tumor on the tongue were used to test the targeting and PTT efficacy of these antibody-PS conjugates in vivo. 30 minutes post injection, nanobodies (7D12-9G8-PS and 7D12-PS) showed similar trends as monoclonal antibody (Cetuximab-PS) which served as control. However, 24 $\mathrm{h}$ later, monoclonal antibody-PS was found to be more effective than nanobody-PS which was attributed to longer half-life of monoclonal antibodies. Treating the tumors $1 \mathrm{~h}$ post injection at $100 \mathrm{~J} / \mathrm{cm}^{2}$ induced tumor 
necrosis in mice injected with nanobody-PS conjugates whereas antibody-PS conjugates did not induce any damage. Additionally, there was no vascular damage in the adjacent tissues due to PDT indicating these nanobodies to possess high specificity.

Anti-EGFR antibodies are another type of protein to target EGFR. Wong and colleagues used polymeric nanoparticles to deliver ICG to tumor cells with the help of anti-EGFR antibodies [151]. Anti-EGFR conjugated nanocapsules were found to be highly specific to two EGFR overexpressing cell lines, 1483 (human head and neck squamous cell) and $\mathrm{SiHa}$ (human cervical squamous cell). Even at a lower power of $6 \mathrm{~W} / \mathrm{cm}^{2}$ and $3 \mathrm{~W} / \mathrm{cm}^{2}$ cells incubated with nanocapsules showed a decrease in cell viability indicating successful targeting and therapy. El-Sayed's group used anti-EGFR antibodies to deliver gold nanoparticles to tumor tissues [172, 213]. Based on the PTT results, anti-EGFR conjugated gold nanoparticles were found to be more effective on malignant cells compared to benign cells. Another study involved use of iron oxide nanoparticles encapsulated in gold nanoshells conjugated to anti-EGFR antibody to target HER2 receptors [173]. Incubation of nanoparticles with cells showed uptake. Gold nanoparticles display lower toxicity compared to other carriers like silica nanoparticles making them better PS for PTT [174, 175]. A unique feature of this study was the use of femtosecond laser to achieve PTT. With a minimal laser power of $20 \mathrm{~mW} / \mathrm{cm}^{2}$ originating from a femtosecond laser, cell death was observed in certain regions indicating lower power lasers could induce the same effect as high power continuous wave lasers. Antibody functionalized gold nanoparticles have been used successfully in antimicrobial PTT [176].

\section{Transferrin}

Transferrin (Tf) has been widely used in cancer therapies for targeting. Transferrin receptors show affinity to iron-carrying transferrin molecules which bind to the transferrin receptors (TfR) and deliver iron to the cells [177]. TfR are expressed at low levels on healthy cells whereas malignant cells tend to overexpress it, depending on the stage of their growth. Tumor tissue requires iron as one of the nutrients in order to sustain and proliferate [178, 179]. Thus, TfR targeting by conjugating $\mathrm{Tf}$ as ligand provides a new targeting method for delivery of therapeutics into the cell. Since the TfR is known to be involved in receptor mediated endocytosis, conjugation of transferrin provides easy access to deliver drugs/ PS in the cell.

Use of transferrin conjugated polymeric nanoparticles in the form of core-shell nanoparticles was reported recently [180]. A gold-polystyrene core-shell nanoparticles loaded with methylene blue was developed for PDT applications. Transferrin-conjugated methylene blue nanoparticles showed higher uptake when incubated with HeLa cells overexpressing transferrin receptors suggesting Tf-TfR based binding and uptake. ROS generation level and hence cell death was higher in HeLa cells compared to the $3 \mathrm{~T} 3$ cells. In another study, $\mathrm{TiO}_{2}$ nanoparticles conjugated to transferrin were used to demonstrate Cerenkov-induced deep phototherapy [140]. $\mathrm{TiO}_{2}$ nanoparticles were conjugated to $\mathrm{Tf}$ which provided for monodisperse particles and enabled receptor-mediated targeting abilities. Tumors shrunk by eight folds within 15 days of treatment in mice xenografted with human fibrosarcoma (HT1080) cells. Similar trends were observed with human lung carcinoma (A549) xenografted mice. Liposomes have also been employed as carriers of the AlPcS4 PS for transferrin mediated active targeting [181]. Transferrin conjugated liposomes were injected into rats bearing bladder tumor and liposomes accumulated in the tumor. Wang and colleagues developed a Tranferrin-IR780 nanoparticle with photodynamic and photothermal capabilities [141]. In vivo experiments on mice bearing CT26 colon carcinoma tumors exhibited nanoparticle accumulation to peak at $48 \mathrm{~h}$ time point (Figure 3A and $3 \mathrm{~B}$ ). PTT displayed an increase in temperature of the tumor to $49.2{ }^{\circ} \mathrm{C}$ resulting in heat induced tumor ablation. Tumor tissue displayed the highest fluorescence ex vivo indicating successful targeting of Tf conjugated nanoparticles (Figure 3C). Laser irradiation of the tumor inhibited tumor growth demonstrating successful targeting and PTT (Figure 3D). Except for the cohort with nanoparticle injection and subsequent laser treatment, none of the harvested tissues showed signs of tissue ablation. The weights of the mice treated with nanoparticles did not vary much compared to the control mice indicating they were healthy (Figure 3E). Gold nanoparticles have also been exploited for active targeting with transferrin conjugation for PTT application [182]. In a similar study, PEG coated gold nanoparticles were conjugated to transferrin and used for PTT studies in vitro [183]. PEG-Tf-NPs displayed 4 folds higher uptake in cells overexpressing folate receptors. Moreover, decrease in cell viability due to PTT was observed with laser irradiation of $7 \mathrm{~W} / \mathrm{cm}^{2}$. 
A
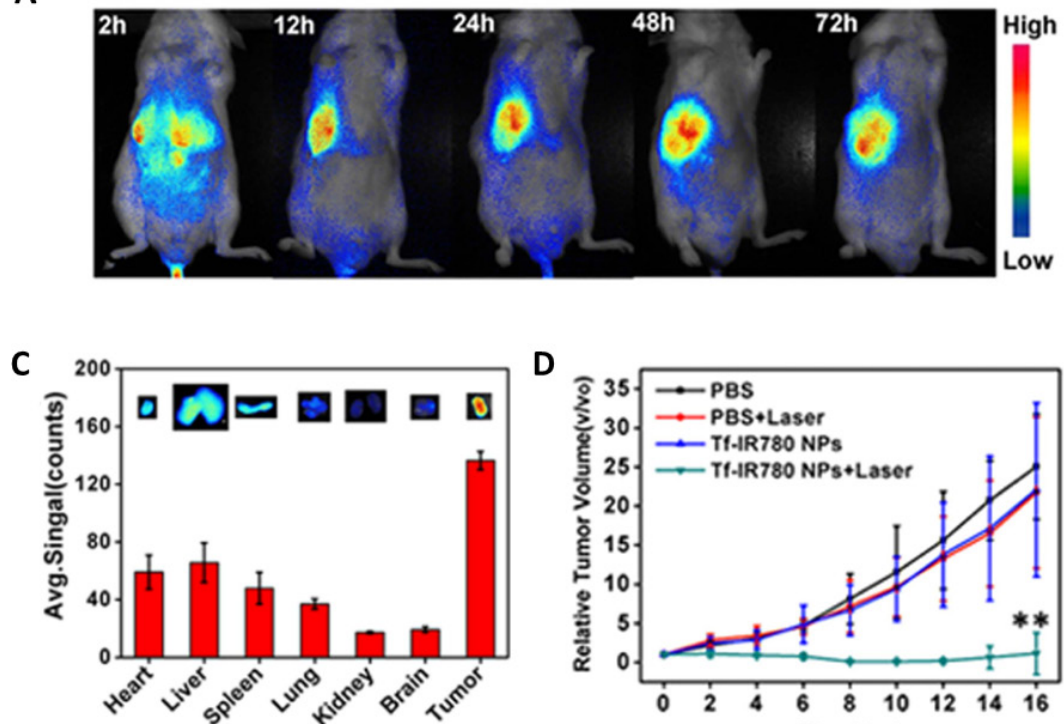

D

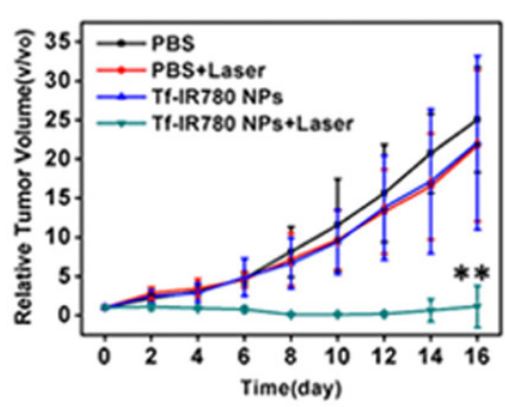

B

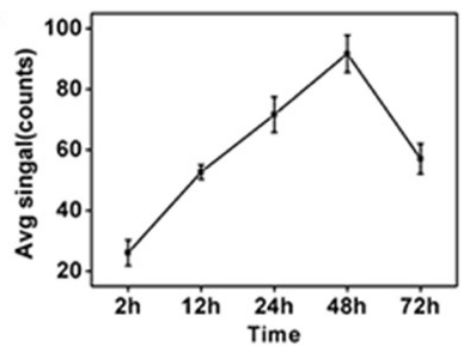

E

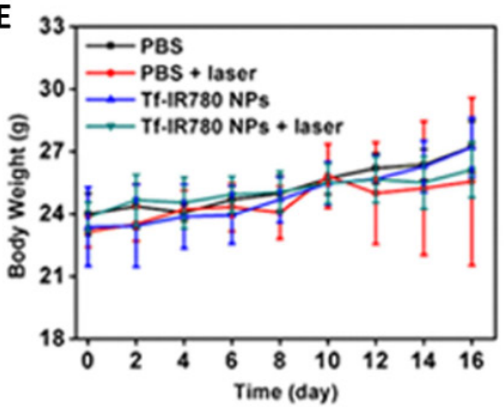

Figure 3: (a) In vivo imaging of transferrin conjugated IR780-nanoparticles at various time-points post i.v. injection. (b) NIR signal recorded in CT26 tumor bearing mice post injection (c) Ex vivo results of tumor bearing mice treated with nanoparticles (d) Growth of tumor with time in mice treated with nanoparticles (e) Body weight of control and treated mice over time. Copyright Nature Publishing Group, 2016. Reproduced with permission from reference [141].

\section{Low-density lipoprotein and other proteins}

Low-density lipoprotein (LDL), a type of protein to solubilize and transport hydrophobic biomolecules like cholesterol, is another attractive targeting ligand in phototherapy [184-186]. LDL receptors are often expressed at a higher level in tumor cells than normal cells because hyperproliferative tumor cells need to utilize the cholesterol for biological membranes and cell growth [187]. Busch and colleagues constructed a reconstituted bacteriochlorin e6 bisoleate low-density lipoprotein (r-Bchl-BOA-LDL) and confirmed its PDT efficacy in nude mice xenografted with HepG2 (human hepatoblastoma) tumor [184]. The reconstituted LDL-PS exhibited a satisfactory PDT effect by ablating tumor completely at 60 days post-PDT and a reduced toxicity to normal tissues. In addition to LDL, a variety of proteins, such as insulin [188], bovine serum albumin [189-191], hematoporphyrin [192], and fibrin [193] have also been employed to deliver PS to tumor via the corresponding receptor protein, which are upregulated in certain types of cancer.

\section{Aptamers}

Aptamers, short nucleotides with specific three-dimensional structure, have been developed as a potential therapeutics. The defined structure of aptamers enables them to bind to a wide variety of targets, including intracellular proteins, transmembrane proteins, carbohydrates, and small molecule drugs. Due to amplification techniques developed for nucleic acids, aptamers can be evolved from combinatorial libraries to virtually any target with high affinity. Scaling up of aptamers is comparatively easy since these moieties can be developed synthetically thereby increasing their availability for research [194]. Therefore, aptamers may be suitable for targeting nanoparticle-based phototherapy. Aptamers can range between $6 \mathrm{kDa}$ and $26 \mathrm{kDa}$ depending on the number of bases. Since they are less bulky compared to antibodies, they may have better access to tiny proteins on the surface of the cell and might be easier to internalize $[195,196]$. Aptamers also provide low immunogenicity apart from the facile synthesis process they offer. For example, AS1411 aptamer was used for targeting and PDT for cancer by Shieh and colleagues [142]. First, AS1411 oligonucleotides were converted to complex structured AS1411 aptamer by dissolving them in saline. AS1411 aptamers were then conjugated to a photosensitive material, 5,10,15,20-tetrakis(1-methylpyridinium-4-yl) porphyrin (TMPyP4) to provide photodynamic capabilities. Incubation of these aptamers with nuceolin overexpressing MCF7 cells resulted in uptake of aptamer-PS conjugates. When irradiated with blue light, cell viability of MCF7 cells incubated with aptamer-PS conjugates drastically reduced indicating specific binding and uptake of aptamers. Aptamers are known to be internalized via specific nucleolin mediated internalization and hence it can be surmised that accumulation of TMPyP4 was higher in MCF-7 cells compared to M10 cells due to nucleolin mediated internalization.

Another interesting class among aptamers 
includes aptamer switch probes (ASP) [197]. ASPs basically act like a switch which can be turned on post targeting. They remain in their dormant state until an externally trigger is used to activate them. Wang and colleagues developed an ASP conjugated to Chlorin-e6 (Ce6) and further conjugated GNRs to the free sulfhydryl groups on the aptamer [197]. Presence of GNRs and aptamer to Ce6 leaves it in the quenched state. The uptake of aptamer would then render it activated which could be used to induce cytotoxicity via PDT. Irradiation with laser resulted in ROS generation and subsequent cell death confirming effective PDT. An interesting aspect to PDT in this study was treatment of cells with white light in addition to $812 \mathrm{~nm}$ laser. CCRF-CCM cells, but not other cell lines, showed cell death when treated with white light. Also, the temperature of the solution rose from $37^{\circ} \mathrm{C}$ to $55^{\circ} \mathrm{C}$ displaying PTT capabilities in vitro in addition to PDT. Thus, aptamers can be used to deliver PDT and PTT agents to generate synergistic effects of dual phototherapy models employing active targeting methods. Aptamer conjugated Au-Ag nanorods have also been demonstrated to be specific to cancer cells [198]. GNRs need to be treated at $10^{5}$ to $10^{10} \mathrm{~W} / \mathrm{m}^{2}$ which might induce damage to the surrounding healthy tissue. Combined $\mathrm{Au}-\mathrm{Ag}$ nanoparticles were able to induce PTT with a laser power of $8.5 \times 10^{4} \mathrm{~W} / \mathrm{m}^{2}$. Aptamer conjugated nanoparticles were selectively internalized and when the co-cultured cells were treated with laser, NB-4 cells (control) remained viable whereas CEM cell line viability decreased exhibiting targeting specificity of aptamers. ICG loaded magnetic graphene oxide conjugates have been explored for synergistic PDT and PTT treatment [199]. sgc8 DNA Aptamers conjugated to magnetic GO served as ligands. Aptamer-graphene oxide conjugates were able to target CCRF-CEM in vitro and induced damage. ICG contributed to PDT generated phototoxicity and presence of graphene oxide resulted in PTT based cell death.

\section{Other receptor ligands}

Folic acid

Folic acid (FA), water soluble vitamin $\mathrm{B}_{9}$, is a promising targeting ligand due to its high binding affinity to folate receptors. Folate receptors are overexpressed on the surface of certain tumor cells compared to healthy cells. Therefore, they tend to be an attractive target for active targeting based therapies [200, 201]. Compared to protein ligands, FA is comparatively abundant to obtain chemically, more stable, smaller in size and non-immunogenic. Given the fact that there can be $10^{7}$ binding sites per cell present on folate overexpressing cells, FA conjugates have generated interest as targeting ligand [202]. Many studies used FA as targeting ligands for targeted PDT and PTT. Zheng's group constructed a folate-porphysome and confirmed its targeted PDT efficacy to folate receptor-overexpressed tumor in mice xenografted with KB tumor [139].

FA-conjugated mesoporpus-silica-coated upconverting fluorescent nanoparticles were developed to deliver PS (MC540, ZnPC) into tumor sites [47]. One of the main advantages of this system was activation of both dyes with the same laser. UCNPs, which make use of NIR light instead of visible light, were employed to achieve more efficient therapeutic effects. FA-conjugated PEG coated UCNPs were tested in a melanoma model in vivo. Dual PS loaded FA-UCNPs were found to selectively target melanoma tumor. Upon the laser treatment, the UCNPs induced cell death and inhibited tumor growth on day 6 and 11 post treatment. In addition to this, mice injected with UCNP prelabeled tumor cells also showed similar trends. Although complete remission was not observed, fine tuning of these nanoparticles might help in achieving optimal results in vivo. In another study, NaYF 4 UCNPs were conjugated to $\mathrm{ZnPc}$, a PS and were functionalized by conjugating FA [138]. UCNPs were synthesized using $\mathrm{Yb}^{3+}$ and $\mathrm{Er}^{3+}$. With minimal FR expression, A549 cells served as negative control and HeLa cells as positive control. UCNPs were internalized by HeLa cells but not by FR- cells indicating successful folate based targeting. A change in morphology of cells with laser irradiation confirmed successful targeting and PDT in vitro. Hepa1-6 tumor induced mice were irradiated with a $980 \mathrm{~nm}$ laser after injecting the nanoparticles intratumorally. 2 weeks after treatment, tumor in the UCNPs treated mice shrunk by over $80 \%$ compared to the control group. In summary, ZnPC loaded upconverting nanoparticles functionalized with FA were developed which could introduce tumor inhibitory effects. Owing to their upconverting properties, these nanoparticles have potential in image-guided PDT treatments. Porphysomes are another emerging class of nanoparticles which carry potential in PDT treatments. FA conjugated porphysomes were used to target FR+ KB tumors in mice [139]. Mice treated with a laser following injection of FA conjugated porphysomes led to complete inhibition of tumor growth within 14 days of treatment. Although some inhibitory effects were seen in porphysomes alone control group, survival data showed a clear trend indicating FA-porphysomes to be the most effective treatment group. FA-graphene-Ce6 nanoparticles were developed for PDT applications [203]. Decrease in the cell viability with laser irradiation after $24 \mathrm{~h}$ 
incubation with FR+ cells showed successful targeting ability of GO nanoparticles. Similarly, GNRs coated with silica have also been explored for FR based targeting for phototherapy [204,205,224-231].

Folate conjugated carbon nanomaterials have been employed to target tumor tissue for phototherapy. Ryu et al. demonstrated the specificity of FA for folate receptors by targeting nanodiamonds (ND) to tumor in KB-tumor induced mice [206]. Noninvasive fluorescence imaging showed that NDs as well as FA-NDs concentrated in the region of tumor; however, FA-NDs showed higher fluorescence at both $1 \mathrm{~h}$ and $72 \mathrm{~h}$ time points (Figure $4 \mathrm{~A}$ ). Ex-vivo analysis displayed higher fluorescence in tumor, especially in mice treated with FA-NDs (Figure 4B). A short 5 min PTT treatment with the help of NIR laser, mice injected with NDs retarded the growth of tumor whereas FA-ND treated mice showed a decrease in the volume of the tumor (Figure $4 \mathrm{C}$ and $4 \mathrm{D}$ ). Thus, folate conjugated carbon nanomaterials can also be used to deliver PDT and PTT agents to desired tissue.

Coating GNRs with silica imparts reduced toxicity, increased stability, and also provides opportunity for functionalization of FA or other ligands on to the surface. Mice implanted with gastric tumor (MGC803) were used to test the efficacy of FA conjugated silica modified GNRs [204]. $12 \mathrm{~h}$ post injection, nanoparticles had spread throughout the tumor with the help of X-ray imaging. These results illustrate the opportunities associated with GNRs in folate assisted targeting of nanoparticles. Other studies have also explored FA targeting for phototherapy [205,224-231].

B
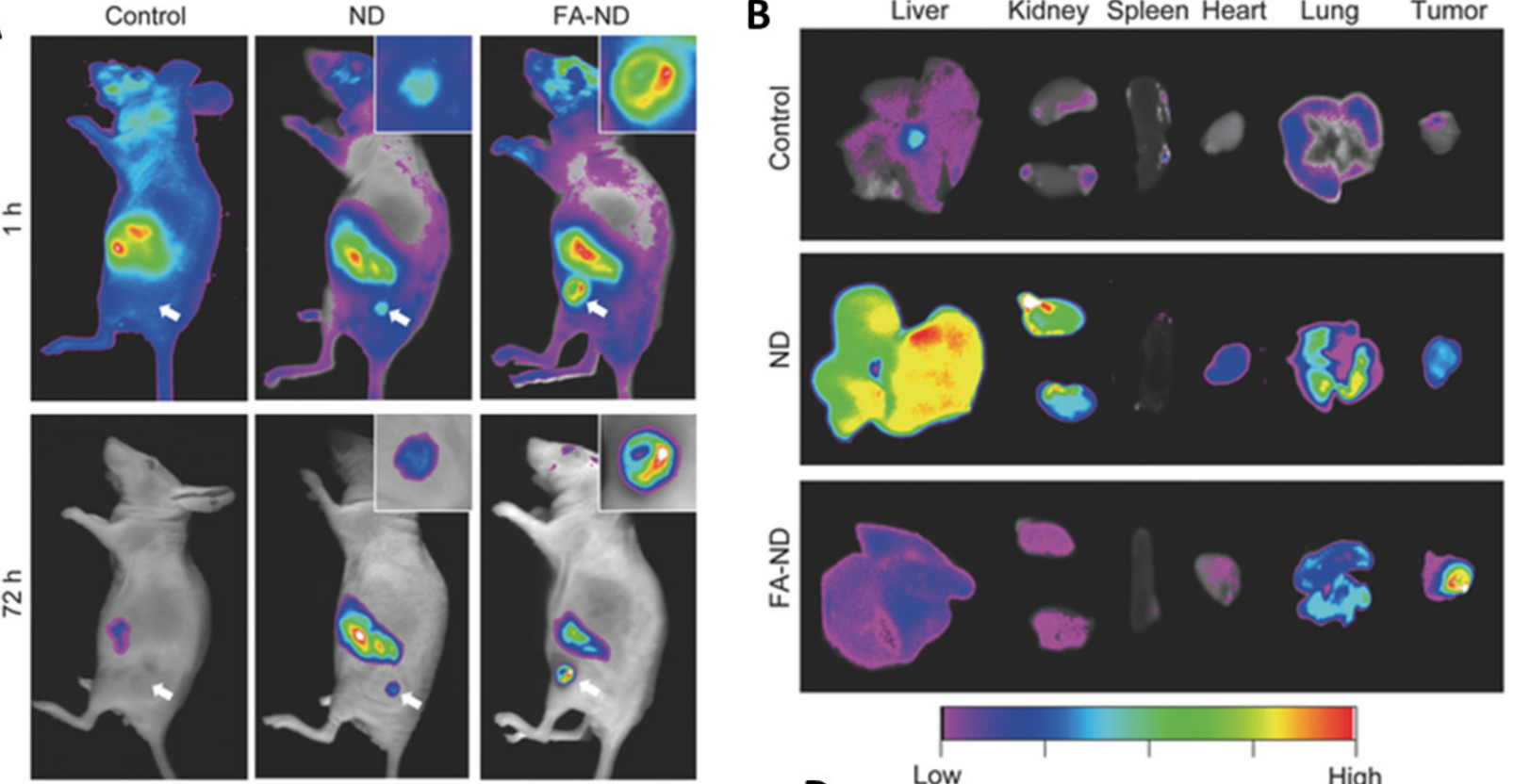

C

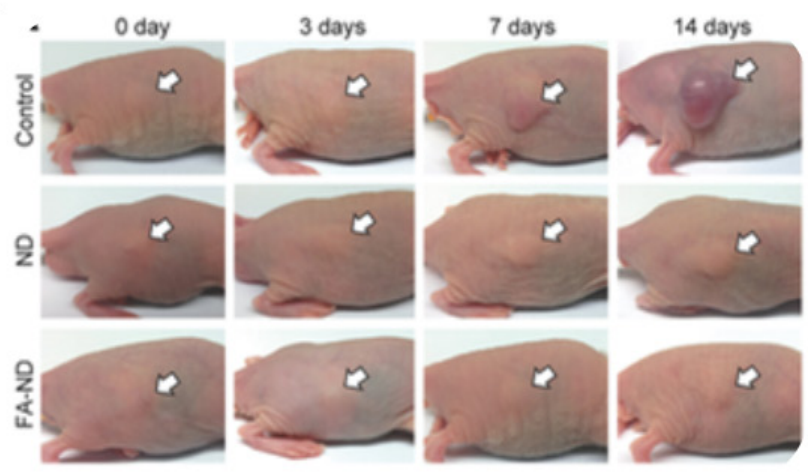

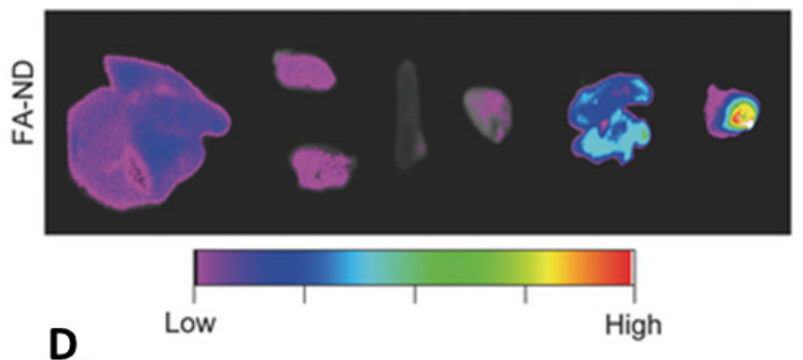

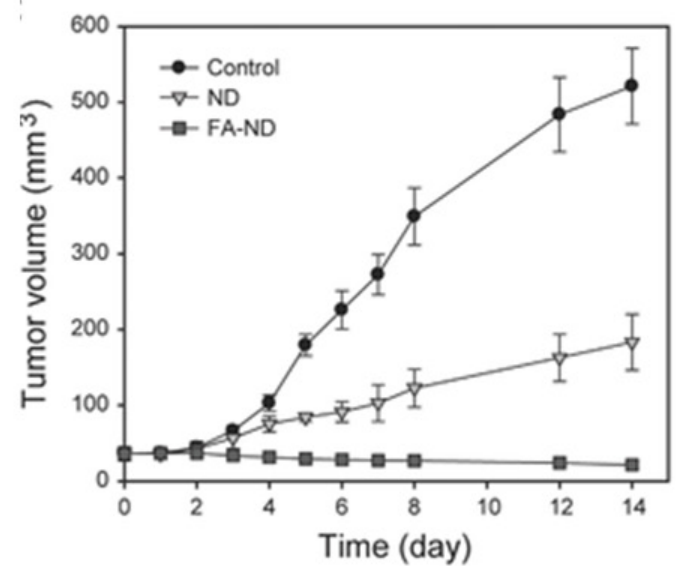

Figure 4: (A)In vivo fluorescence imaging of mice at two time points (B) Ex vivo fluorescence imaging of mice treated with $+/-$ folic acid nanodiamonds (C) Photothermal therapy treatment on mice bearing tumors injected with nanodiamonds and imaged at indicated time-points (D) Tumor volume monitored over a period of 14 days post treatment. Copyright Wiley, 2016. Reproduced with permission from reference [206]. 


\section{Carbohydrates}

A targeted PS approach using pyropheophorbide 2-deoxyglucosamide (Pyro-2DG) to target glucose transporters has been reported [207, 208]. This approach follows the highly successful fludeoxyglucose probe which targets up-regulated glucose transporters and has been validated in clinical positron emission tomography. The targeting and PDT efficacy of Pyro-2DG was examined in 9L rat gliomas. The results demonstrated that Pyro-2DG selectively accumulated in the tumor via the GLUT/hexokinase pathway and resulted in selective mitochondrial damage upon irradiation. Upon light irradiation, there was a correlation between photobleaching of Pyro-2DG and tumor destruction [208]. Several other carbohydrate-targeted photosensitizers have been developed [209-211].

\section{Surface modified nanomaterials}

Modifying the surface chemistry of nanoparticles to deliver phototherapeutic agents via active targeting has been employed frequently. Several types of nanoparticles ranging from polymers to gold nanoparticles to carbon nanotubes have been subjected to bioconjugation rendering them with active targeting capabilities. Ligands on surface modified materials show affinity to specific receptors resulting in improved phototherapeutic efficacy. Polymeric surface-modified gold nanoparticles have been employed in photothermal therapy applications [212]. Polymeric micelles and polymers-PS conjugates have also found application in PDT applications [214]. Modified cationic PEI polymer with free sulfate residues was used to target selectin overexpressing cells. Irradiating the cells after a short incubation with polymer-PS conjugate displayed lower cell viability in selectin overexpressing cells leading to effective PDT [215]. In a study involving dual PDT and PTT, performance of UCNP as synergistic PDT and PTT carrier was evaluated [216]. BSA coated UCNPs were conjugated to polyacrylic acid and loaded with Rose Bengal and IR825 dyes. PDT or PTT alone showed tumor growth inhibition but synergistic PDT-PTT treatment showed higher tumor growth inhibition suggesting multi-therapy treatment resulting in synergistic effects. However, multidye nanoparticles may require multilaser excitation which makes it difficult to translate these to the clinic.

\section{Hyaluronic acid (HA)}

Hyaluronic acid-mediated targeting attracts interests due to its unique glycosaminoglycan structure and high binding affinity to hyaluronan-mediated motility receptor and glycoprotein CD44, typically overexpressed by various tumor cells [217]. Hyaluronidase present in the extracellular matrix can break down these nanoparticles thus releasing their cargo. Targeting, facile synthesis, improved drug loading capabilities are some of the advantages of HA approaches. HA is cleaved by hyaluronidase, causing carriers to release their contents. HA based nanoparticles can also be combined with proteins which might generate particles with multiple targeting capabilities.

In a recent study, a PEG and cholanic acid modified HA nanoparticle (HANPs) loaded with the PS Ce6 was studied as the PDT agent [143]. With the addition of a quencher, dark toxicity originating from nonspecific tissue was reduced as the nanoparticles are delivered in their quenched form. HANPs concentrated in the tumor within $4 \mathrm{~h}$ of injection. Fluorescence originating from the tumor showed almost an order of magnitude higher fluorescence compared to mice injected with free Ce6. Phototherapy results showed $73 \%$ tumor shrinking compared to controls. Thus, HANPs displayed successful targeting and phototherapeutic potential based on the tumor growth inhibition results. Another group used a similar strategy to target nanoparticles to CD44 expressing cancer cells [218]. HA nanoparticles modified with cholanic acid were seen to be internalized by squamous cell carcinoma cell in vitro which was attributed to overexpression of CD44 on the surface. In vivo, based on fluorescence originating from the tumor, HA nanoparticles concentrated in the region of tumor indicating high tumor specificity for CD44 expressing tumors. Unmodified HANPs were not as effective and were cleared out in an hour thus proving HA modification to be a necessary step in order to provide longer half-life and effective targeting abilities.

Li et al. developed activatable HA nanoparticles modified using adipic dihydrazide. Modified HA nanoparticles were conjugated to chlorin e6 PS which rendered phototherapeutic capabilities to HA nanoparticles [219]. As shown in Figure 5A and 5B, HANPs were able to accumulate in tumor and peaked at $24 \mathrm{~h}$ post injection whereas free Ce6 was cleared quickly. Biodistribution results confirmed the targeting of nanoparticles since free ce6 accumulated mostly in liver whereas HANPs accumulated in tumor liver and kidney (Figure 5C and 5D). Photoacoustic imaging showed the accumulation of nanoparticles in the region of tumor (Figure 5E and 5F). Post PDT treatment, tumor volume reduced by $93 \%$ in two weeks. These results demonstrate that the nanoparticles were able to target via CD44 receptors on the surface of tumor cells successfully. A new photodynamic PS, DTDPP, was developed by coupling to HA [220]. In vivo tests were carried out on 
HCT-116 tumor-bearing mice. HA-PS was able to target tumor with high specificity and post laser irradiation, tumor completely shrunk 40 days after treatment.

A graphene oxide based GO-HA-Ce6 nanoparticle was developed for PDT [221]. These GO-HA-Ce6 nanoparticles were seen to accumulate in HeLa cells selectively indicating specificity to CD44 expressing cells. Upon irradiation with laser, cell viability was reduced suggesting GO-HA-Ce6 nanoparticles to possess phototherapeutic capabilities. These results suggest modified-HA nanoparticles can deliver the cargo to CD44 receptor rich regions and serve as a new class of phototherapy carriers.
A)

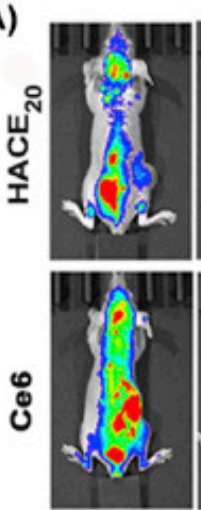

$1 \mathrm{~h}$
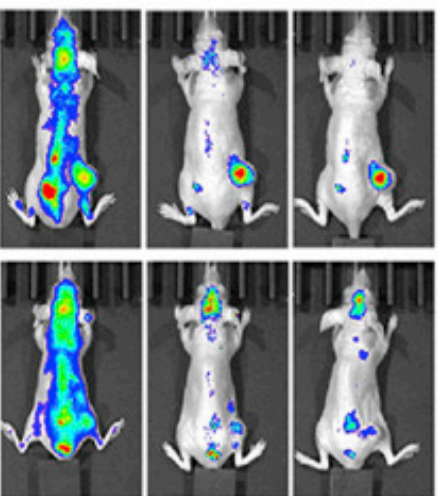

$8 \mathrm{~h}$

C)

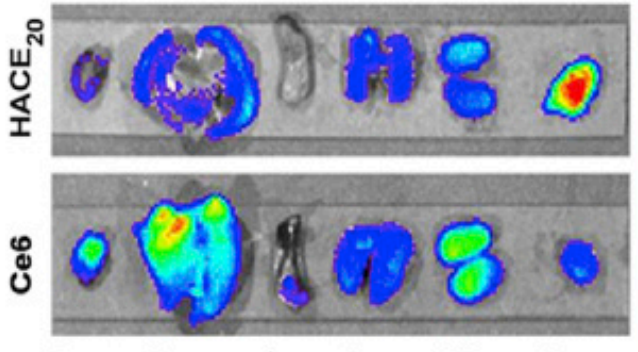

Heart liver spleen Lung Kidney Tumor

E)

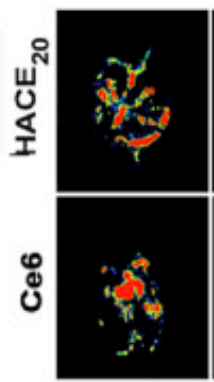

$\mathbf{O h}$

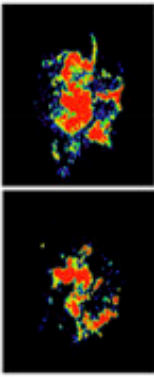

$1 \mathrm{~h}$

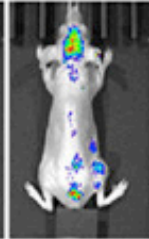

$24 \mathrm{~h}$

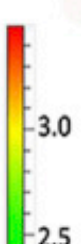

B)

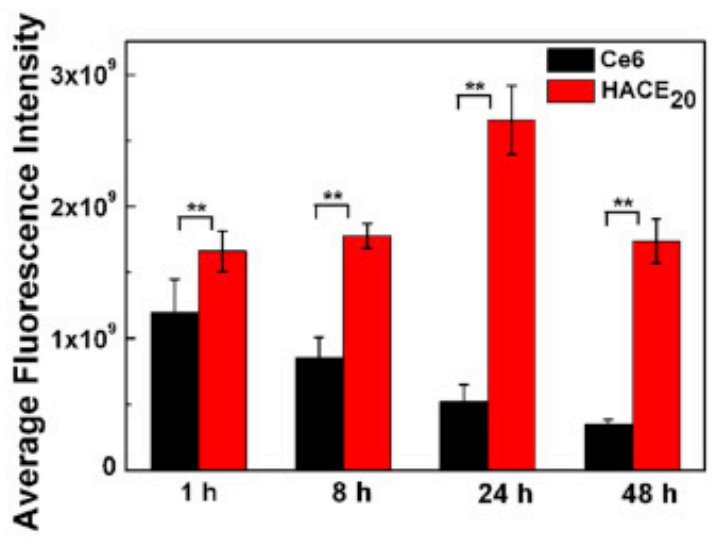

D)

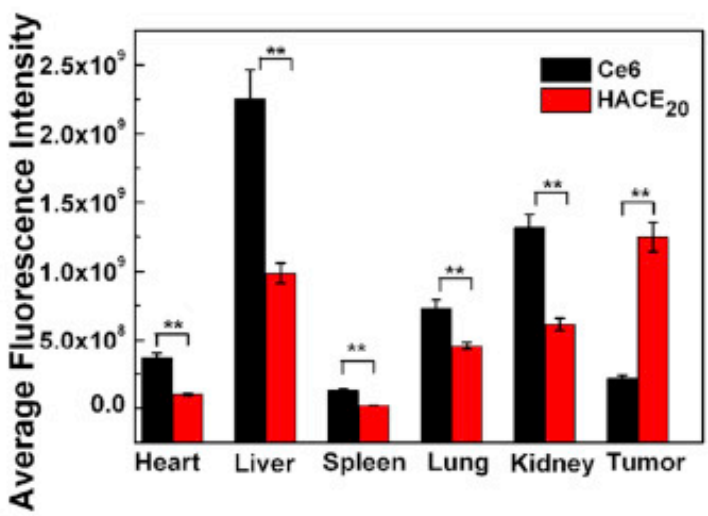

F)

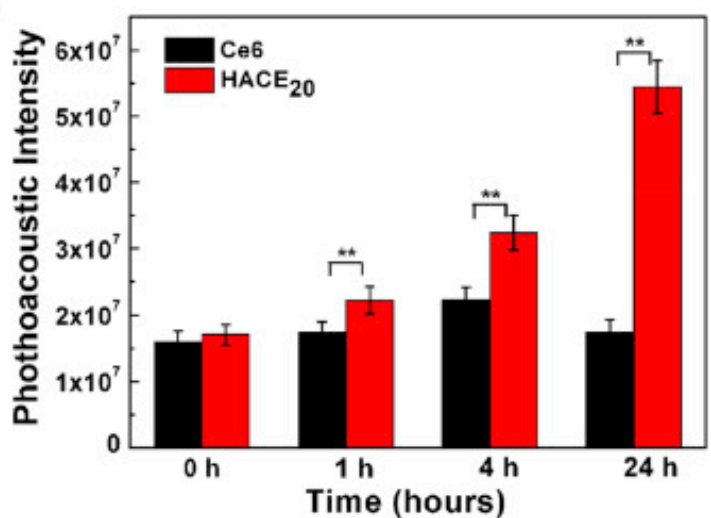

Figure 5: (a) Imaging of Ce6 and HANPs post injection in mice bearing tumor (b) Quantification of signal intensity at the tumor site (c) Ex vivo NIR images of organs $24 \mathrm{~h}$ post treatment (d) Quantification of signal intensity from ex vivo studies (e) Photoacoustic imaging of mice injected with HANPs (f) Quantification of signal intensity in the region of interest. Copyright Elsevier, 2016. Reproduced with permission from reference [219]. 


\section{Conclusion}

Although phototherapy itself is an inherently targeted system owing to selective light application, molecular targeting can further enhance the selectivity and efficacy. While this can provide a higher level of selectivity, the additional complexity needs to be justified in order for the materials to progress into human trials. Preclinical studies have demonstrated the feasibility of enhanced delivery of phototherapy agents to targeted tissues using ligand-based active targeting. Dark toxicity associated with non-targeted phototherapy delivery could potentially be reduced since lower injected doses might be required to achieve therapeutic effects. While preclinical research activity is expected to remain high, phototherapeutic targeted nanoparticles are still in a relatively nascent stage with respect to clinical translation. Therefore, comprehensive data showing clear-cut advantages over conventional PS, and large animal studies will be advantageous for the translation from bench to clinic.

\section{Acknowledgements}

This work was supported by the National Institutes of Health (R01EB017270 and DP5OD017898).

\section{Competing Interests}

The authors have declared that no competing interest exists.

\section{References}

1. Ackroyd R, Kelty C, Brown N, Reed M. The history of photodetection and photodynamic therapy. Photochem Photobiol. 2001; 74: 656-69.

2. Pushpan S, Venkatraman S, Anand V, Sankar J, Parmeswaran D, Ganesan S, et al. Porphyrins in photodynamic therapy-a search for ideal photosensitizers. Curr Med Chem Anti-Cancer Agents. 2002; 2: 187-207.

3. Roelandts R. The history of phototherapy: Something new under the sun? J Am Acad Dermatol. 2002; 46: 926-30.

4. Roelandts R. A new light on Niels Finsen, a century after his Nobel Prize. Photodermatol Photoimmunol Photomed. 2005; 21: 115-7.

5. Betsy J, Prasanth CS, Baiju KV, Presanthila J, Subhash N. Patients' perceptions of antimicrobial photodynamic therapy in the management of chronic periodontitis. Photodiagnosis Photodynamic Therapy. 2016; 14: 84-90.

6. de Freitas LM, Calixto GM, Chorilli M, Giusti JS, Bagnato VS, Soukos NS, et al. Polymeric Nanoparticle-Based Photodynamic Therapy for Chronic Periodontitis in Vivo. Int J Mol Sci. 2016; 17: 769; DOI:10.3390/ijms17050769

7. Yazdani Abyaneh MA, Falto-Aizpurua L, Griffith RD, Nouri K. Photodynamic therapy for actinic cheilitis: a systematic review. Dermatol Surg. 2015; 41: 189-98.

8. Lin J, Wang $\mathrm{M}$, Hu $\mathrm{H}$, Yang $\mathrm{X}$, Wen $\mathrm{B}$, Wang $\mathrm{Z}$, et al. Multimodal-Imaging-Guided Cancer Phototherapy by Versatile Biomimetic Theranostics with UV and gamma-Irradiation Protection. Ad Mater. 2016; 28: 3273-9.

9. Guo R, Peng H, Tian Y, Shen S, Yang W. Mitochondria-Targeting Magnetic Composite Nanoparticles for Enhanced Phototherapy of Cancer. Small. 2016, in press. DOI: 10.1002/smll.201601094.

10. Sheng Z, Hu D, Zheng M, Zhao P, Liu H, Gao D, et al. Smart human serum albumin-indocyanine green nanoparticles generated by programmed assembly for dual-modal imaging-guided cancer synergistic phototherapy. ACS Nano. 2014; 8: 12310-22.

11. Pekkanen AM, DeWitt MR, Rylander MN. Nanoparticle enhanced optical imaging and phototherapy of cancer. I Biomed NanotechnoL. 2014; 10: 1677-712.

12. Wang D, Fei B, Halig LV, Qin $\mathrm{X}, \mathrm{Hu} \mathrm{Z}, \mathrm{Xu} \mathrm{H}$, et al. Targeted iron-oxide nanoparticle for photodynamic therapy and imaging of head and neck cancer. ACS Nano. 2014; 8: 6620-32.
13. Moore CM, Pendse D, Emberton M. Photodynamic therapy for prostate cancer--a review of current status and future promise. Nat Clin Prac Urol. 2009; 6: 18-30.

14. Agostinis P, Berg K, Cengel KA, Foster TH, Girotti AW, Gollnick SO, et al. Photodynamic therapy of cancer: An update. CA: Cancer J Clinic. 2011; 61: 250-81.

15. Huang H, Lovell JF. Advanced Functional Nanomaterials for Theranostics. Adv Func Mater. 2016, in press. DOI: 10.1002/adfm.201603524.

16. Luo D, Carter KA, Lovell JF. Nanomedical engineering: shaping future nanomedicines. WIRES: Nanomed Nanobiotechnol. 2015; 7: 169-88.

17. Luo D, Carter KA, Miranda D, Lovell JF. Chemophototherapy: An Emerging Treatment Option for Solid Tumors. Adv Sci. 2016, in press. DOI: 10.1002/advs.201600106.

18. Dolmans DEJGJ, Fukumura D, Jain RK. Photodynamic therapy for cancer. Nat Rev Cancer. 2003; 3: 380-7.

19. Oleinick NL, Evans HH. The photobiology of photodynamic therapy: cellular targets and mechanisms. Radiation Res. 1998; 150: S146-S56.

20. Brown SB, Brown EA, Walker I. The present and future role of photodynamic therapy in cancer treatment. Lancet Oncol. 2004; 5: 497-508.

21. Allison RR, Moghissi K. Photodynamic Therapy (PDT): PDT mechanisms. Clin Endoscopy. 2013; 46: 24-9.

22. Zou L, Wang H, He B, Zeng L, Tan T, Cao H, et al. Current approaches of photothermal therapy in treating cancer metastasis with nanotherapeutics. Theranostics. 2016; 6: 762-72.

23. Zhu X, Feng W, Chang J, Tan YW, Li J, Chen M, et al. Temperature-feedback upconversion nanocomposite for accurate photothermal therapy at facile temperature. Nat Commun. 2016; 7: 10437.

24. Xing $\mathrm{R}$, Liu $\mathrm{K}$, Jiao $\mathrm{T}$, Zhang $\mathrm{N}$, Ma K, Zhang $\mathrm{R}$, et al. An injectable self-assembling collagen-gold hybrid hydrogel for combinatorial antitumor photothermal/photodynamic therapy. Adv Mat. 2016; 28: 3669-76.

25. Lovell JF, Liu TW, Chen J, Zheng G. Activatable photosensitizers for imaging and therapy. Chem Rev. 2010; 110: 2839-57.

26. Byrne JD, Betancourt T, Brannon-Peppas L. Active targeting schemes for nanoparticle systems in cancer therapeutics. Adv Drug Deliv Rev. 2008; 60: 1615-26.

27. Iyer AK, Khaled G, Fang J, Maeda H. Exploiting the enhanced permeability and retention effect for tumor targeting. Drug Discov Today. 2006; 11: 812-8.

28. Battersby AR. Tetrapyrroles: the pigments of life. Nat Prod Rep. 2000; 17: 507-26.

29. Zhang Y, Lovell JF. Porphyrins as theranostic agents from prehistoric to modern times. Theranostics. 2012; 2: 905-15.

30. Huang H, Song W, Rieffel J, Lovell JF. Emerging applications of porphyrins in photomedicine. Frontiers Physics. 2015; 3. DOI: 10.3389/fphy.2015.00023.

31. Zhang Y, Lovell JF. Recent applications of phthalocyanines and naphthalocyanines for imaging and therapy. WIRES: Nanomed Nanobiotechnol. 2016, in press. DOI: $10.1002 /$ wnan. 1420.

32. Abrahamse $\mathrm{H}, \mathrm{Hamblin}$ MR. New photosensitizers for photodynamic therapy. Biochem J. 2016; 473: 347-64.

33. Bonnett R. Photosensitizers of the porphyrin and phthalocyanine series for photodynamic therapy. Chem Soc Rev. 1995; 24: 19-33.

34. Urbanska K, Romanowska-Dixon B, Matuszak Z, Oszajca J, Nowak-Sliwinska $P$, Stochel G. Indocyanine green as a prospective sensitizer for photodynamic therapy of melanomas. Acta Biochim Polonica. 2002; 49: 387-91.

35. Barth BM, Altinoglu EI, Shanmugavelandy SS, Kaiser JM, Crespo-Gonzalez D, DiVittore NA, et al. Targeted Indocyanine-Green-Loaded Calcium Phosphosilicate Nanoparticles for In Vivo Photodynamic Therapy of Leukemia. ACS Nano. 2011; 5: 5325-37.

36. Shrestha A, Kishen A. Polycationic Chitosan-Conjugated Photosensitizer for Antibacterial Photodynamic Therapy. Photochem Photobiol. 2012; 88: 577-83.

37. Barras A, Boussekey L, Courtade E, Boukherroub R. Hypericin-loaded lipid nanocapsules for photodynamic cancer therapy in vitro. Nanoscale. 2013; 5: 10562-72.

38. Nafee N, Youssef A, El-Gowelli H, Asem H, Kandil S. Antibiotic-free nanotherapeutics: hypericin nanoparticles thereof for improved in vitro and in vivo antimicrobial photodynamic therapy and wound healing. Int J Pharm. 2013; 454: 249-58.

39. Zhao H, Yin R, Chen D, Ren J, Wang Y, Zhanga J, et al. In vitro and in vivo antitumor activity of a novel hypocrellin B derivative for photodynamic therapy. Photodiagnosis Photodynamic Therapy. 2014; 11: 204-12.

40. Sato K, Sakakibara N, Minami H, Tsuji T. New promising photodynamic therapy: Dermal injection of riboflavin and near-ultraviolet/visible radition. $J$ Invest Dermatol. 1997; 108: 773.

41. Leite DP, Paolillo FR, Parmesano TN, Fontana CR, Bagnato VS. Effects of photodynamic therapy with blue light and curcumin as mouth rinse for oral disinfection: a randomized controlled trial. Photomed Laser Surg. 2014; 32: 627-32.

42. Ellerkamp V, Bortel N, Schmid E, Kirchner B, Armeanu-Ebinger S, Fuchs J. Photodynamic Therapy Potentiates the Effects of Curcumin on Pediatric Epithelial Liver Tumor Cells. Anticancer Res. 2016; 36: 3363-72.

43. Ebermann R, Alth G, Kreitner M, Kubin A. Natural products derived from plants as potential drugs for the photodynamic destruction of tumor cells. J Photochem Photobiol B. 1996; 36: 95-7.

44. Zhang $\mathrm{H}$, Shan $\mathrm{Y}$, Dong L. A comparison of $\mathrm{TiO} 2$ and $\mathrm{ZnO}$ nanoparticles as photosensitizers in photodynamic therapy for cancer. J Biomedical Nanotechnol. 2014; 10: 1450-7. 
45. Hsu CY, Chen CW, Yu HP, Lin YF, Lai PS. Bioluminescence resonance energy transfer using luciferase-immobilized quantum dots for self-illuminated photodynamic therapy. Biomaterials. 2013; 34: 1204-12.

46. Samia AC, Chen X, Burda C. Semiconductor quantum dots for photodynamic therapy. J Am Chem Soc. 2003; 125: 15736-7.

47. Idris NM, Gnanasammandhan MK, Zhang J, Ho PC, Mahendran R, Zhang Y. In vivo photodynamic therapy using upconversion nanoparticles as remote-controlled nanotransducers. Nature Med. 2012; 18: 1580-5.

48. Wang C, Tao H, Cheng L, Liu Z. Near-infrared light induced in vivo photodynamic therapy of cancer based on upconversion nanoparticles. Biomaterials. 2011; 32: 6145-54

49. Hu Y, Yang Y, Wang H, Du H. Synergistic integration of layer-by-layer assembly of photosensitizer and gold nanorings for enhanced photodynamic therapy in the near infrared. ACS Nano. 2015; 9: 8744-54.

50. Shi Z, Ren W, Gong A, Zhao X, Zou Y, Brown EM, et al. Stability enhanced polyelectrolyte-coated gold nanorod-photosensitizer complexes for high/low power density photodynamic therapy. Biomaterials. 2014; 35: 7058-67.

51. Teng IT, Chang YJ, Wang LS, Lu HY, Wu LC, Yang CM, et al. Phospholipid-functionalized mesoporous silica nanocarriers for selective photodynamic therapy of cancer. Biomaterials. 2013; 34: 7462-70.

52. Gary-Bobo M, Mir Y, Rouxel C, Brevet D, Basile I, Maynadier M, et al Mannose-functionalized mesoporous silica nanoparticles for efficient two-photon photodynamic therapy of solid tumors. Angewandte Chem Int Ed. 2011; 50: 11425-9.

53. Zhang L, Zeng L, Pan Y, Luo S, Ren W, Gong A, et al. Inorganic photosensitizer coupled Gd-based upconversion luminescent nanocomposites for in vivo magnetic resonance imaging and near-infrared-responsive photodynamic therapy in cancers. Biomaterials. 2015; 44: 82-90.

54. Rieffel J, Chitgupi U, Lovell JF. Recent advances in higher-order, multimodal, biomedical imaging agents. Small. 2015; 11: 4445-61.

55. Jaque D, Martinez Maestro L, del Rosal B, Haro-Gonzalez P, Benayas A, Plaza JL, et al. Nanoparticles for photothermal therapies. Nanoscale. 2014; 6: 9494-530.

56. Hirsch LR, Stafford RI, Bankson JA, Sershen SR, Rivera B, Price RE, et al. Nanoshell-mediated near-infrared thermal therapy of tumors under magnetic resonance guidance. Proc Natl Acad Sci. 2003; 100: 13549-54.

57. Liu Y, Ashton JR, Moding EJ, Yuan H, Register JK, Fales AM, et al. A Plasmonic Gold Nanostar Theranostic Probe for In Vivo Tumor Imaging and Photothermal Therapy. Theranostics. 2015; 5: 946-60.

58. Jang B, Park JY, Tung CH, Kim IH, Choi Y. Gold nanorod-photosensitizer complex for near-infrared fluorescence imaging and photodynamic/photothermal therapy in vivo. ACS Nano. 2011; 5: 1086-94.

59. Yu M, Guo F, Wang J, Tan F, Li N. Photosensitizer-Loaded pH-Responsive Hollow Gold Nanospheres for Single Light-Induced Photothermal/Photodynamic Therapy. ACS Appl Mat interfaces. 2015; 7: $17592-7$.

60. Mooney R, Roma L, Zhao D, Van Haute D, Garcia E, Kim SU, et al. Neural stem cell-mediated intratumoral delivery of gold nanorods improves photothermal therapy. ACS Nano. 2014; 8: 12450-60.

61. Yang G, Lv R, He F, Qu F, Gai S, Du S, et al. A core/shell/satellite anticancer platform for 808 NIR light-driven multimodal imaging and combined chemo-/photothermal therapy. Nanoscale. 2015; 7: 13747-58.

62. Yang D, Yang G, Wang X, Lv R, Gai S, He F, et al. Y2O3:Yb,Er@mSiO2-Cu(x)S double-shelled hollow spheres for enhanced chemo-/photothermal anti-cancer therapy and dual-modal imaging. Nanoscale. 2015; 7: 12180-91.

63. Lv R, Yang P, He F, Gai S, Yang G, Dai Y, et al. An imaging-guided platform for synergistic photodynamic/photothermal/chemo-therapy with $\mathrm{pH}$ /temperature-responsive drug release. Biomaterials. 2015; 63: 115-27.

64. Xiao Q, Zheng X, Bu W, Ge W, Zhang S, Chen F, et al. A core/satellite multifunctional nanotheranostic for in vivo imaging and tumor eradication by radiation/photothermal synergistic therapy. J Am Chem Soc. 2013; 135: 13041-8.

65. Huang X, Li B, Peng C, Song G, Peng Y, Xiao Z, et al. NaYF4:Yb/Er@PPy core-shell nanoplates: an imaging-guided multimodal platform for photothermal therapy of cancers. Nanoscale. 2016; 8: 1040-8.

66. Liu T-M, Conde J, Lipiński T, Bednarkiewicz A, Huang C-C. Revisiting the classification of NIR-absorbing/emitting nanomaterials for in vivo bioapplications. NPG Asia Mat. 2016; 8: e295.

67. Jung HS, Kong WH, Sung DK, Lee MY, Beack SE, Keum do H, et al. Nanographene oxide-hyaluronic acid conjugate for photothermal ablation therapy of skin cancer. ACS Nano. 2014; 8: 260-8.

68. Markovic ZM, Harhaji-Trajkovic LM, Todorovic-Markovic BM, Kepic DP, Arsikin KM, Jovanovic SP, et al. In vitro comparison of the photothermal anticancer activity of graphene nanoparticles and carbon nanotubes. Biomaterials. 2011; 32: 1121-9.

69. Liang C, Diao S, Wang C, Gong H, Liu T, Hong G, et al. Tumor Metastasis Inhibition by Imaging-Guided Photothermal Therapy with Single-Walled Carbon Nanotubes. Adv Mat. 2014; 26: 5646-52.

70. Chu M, Pan X, Zhang D, Wu Q, Peng J, Hai W. The therapeutic efficacy of $\mathrm{CdTe}$ and CdSe quantum dots for photothermal cancer therapy. Biomaterials. 2012; 33: 7071-83.

71. Gao J, Wu C, Deng D, Wu P, Cai C. Direct Synthesis of Water-Soluble Aptamer-Ag2S Quantum Dots at Ambient Temperature for Specific Imaging and Photothermal Therapy of Cancer. Adv Healthcare Mat. 2016; 5: 2437-49.

72. Yong Y, Cheng X, Bao T, Zu M, Yan L, Yin W, et al. Tungsten Sulfide Quantum Dots as Multifunctional Nanotheranostics for In Vivo Dual-Modal
Image-Guided Photothermal/Radiotherapy Synergistic Therapy. ACS Nano. 2015; 9: 12451-63.

73. Courtney CM, Goodman SM, McDaniel JA, Madinger NE, Chatterjee A, Nagpal P. Photoexcited quantum dots for killing multidrug-resistant bacteria. Nat Mat. 2016; 15: 529-34.

74. Zhang X, Li N, Liu Y, Ji B, Wang Q, Wang M, et al. On-demand drug release of ICG-liposomal wedelolactone combined photothermal therapy for tumor. Nanomed Nanotechnol Biol Med. 2016; 12: 2019-2029.

75. Jian WH, Yu TW, Chen CJ, Huang WC, Chiu HC, Chiang WH. Indocyanine Green-Encapsulated Hybrid Polymeric Nanomicelles for Photothermal Cancer Therapy. Langmuir. 2015; 31: 6202-10.

76. Sharker SM, Lee JE, Kim SH, Jeong JH, In I, Lee H, et al. pH triggered in vivo photothermal therapy and fluorescence nanoplatform of cancer based on responsive polymer-indocyanine green integrated reduced graphene oxide. Biomaterials. 2015; 61: 229-38.

77. Ng KK, Takada M, Jin CC, Zheng G. Self-sensing porphysomes for fluorescence-guided photothermal therapy. Bioconjugate Chem. 2015; 26: 345-51.

78. Jin CS, Lovell JF, Chen J, Zheng G. Ablation of hypoxic tumors with dose-equivalent photothermal, but not photodynamic, therapy using a nanostructured porphyrin assembly. ACS Nano. 2013; 7: 2541-50.

79. Rieffel J, Chen F, Kim J, Chen G, Shao W, Shao S, et al. Hexamodal Imaging with Porphyrin-Phospholipid-Coated Upconversion Nanoparticles. Adv Mat. 2015; 27: 1785-90.

80. Shao S, Geng J, Ah Yi H, Gogia S, Neelamegham S, Jacobs A, et al. Functionalization of cobalt porphyrin-phospholipid bilayers with his-tagged ligands and antigens. Nat Chem. 2015; 7: 438-46.

81. Luo D, Carter KA, Razi A, Geng J, Shao S, Giraldo D, et al. Doxorubicin encapsulated in stealth liposomes conferred with light-triggered drug release. Biomaterials. 2016; 75: 193-202.

82. Carter KA, Shao S, Hoopes MI, Luo D, Ahsan B, Grigoryants VM, et al. Porphyrin-phospholipid liposomes permeabilized by near-infrared light. Nat Commun. 2014; 5: 3546.

83. Luo D, Carter KA, Razi A, Geng J, Shao S, Lin C, et al. Porphyrin-phospholipid liposomes with tunable leakiness. J Controlled Release. 2015; 220(Part A): 484-94.

84. Lovell JF, Jin CS, Huynh E, Jin H, Kim C, Rubinstein JL, et al. Porphysome nanovesicles generated by porphyrin bilayers for use as multimodal biophotonic contrast agents. Nat Mat. 2011; 10: 324-32.

85. Shao S, Do TN, Razi A, Chitgupi U, Geng J, Alsop RJ, et al. Design of Hydrated Porphyrin-Phospholipid Bilayers with Enhanced Magnetic Resonance Contrast. Small. 2016, in press. DOI: 10.1002/smll.201602505.

86. Lin J, Wang S, Huang P, Wang Z, Chen S, Niu G, et al. Photosensitizer-loaded gold vesicles with strong plasmonic coupling effect for imaging-guided photothermal/photodynamic therapy. ACS Nano. 2013; 7: 5320-9.

87. Sahu A, Choi WI, Lee JH, Tae G Graphene oxide mediated delivery of methylene blue for combined photodynamic and photothermal therapy. Biomaterials. 2013; 34: 6239-48.

88. Zheng M, Liu S, Li J, Xie ZG, Qu D, Miao X, et al. Preparation of highly luminescent and color tunable carbon nanodots under visible light excitation for in vitro and in vivo bio-imaging. J Mat Res. 2015; 30: 3386-93.

89. Ge J, Jia Q, Liu W, Lan M, Zhou B, Guo L, et al. Carbon Dots with Intrinsic Theranostic Properties for Bioimaging, Red-Light-Triggered Photodynamic/Photothermal Simultaneous Therapy In Vitro and In Vivo. Adv Healthcare Mat. 2016; 5: 665-75.

90. Wang J, Zhang Z, Zha S, Zhu Y, Wu P, Ehrenberg B, et al. Carbon nanodots featuring efficient FRET for two-photon photodynamic cancer therapy with a low fs laser power density. Biomaterials. 2014; 35: 9372-81.

91. Huang P, Lin J, Wang X, Wang Z, Zhang C, He M, et al. Light-triggered theranostics based on photosensitizer-conjugated carbon dots for simultaneous enhanced-fluorescence imaging and photodynamic therapy. Adv Mat. 2012; 24: 5104-10.

92. Yan F, Wu H, Liu H, Deng Z, Liu H, Duan W, et al. Molecular imaging-guided photothermal/photodynamic therapy against tumor by iRGD-modified indocyanine green nanoparticles. J Controlled Release. 2016; 224: 217-28.

93. Vijayaraghavan P, Liu CH, Vankayala R, Chiang CS, Hwang KC. Designing multi-branched gold nanoechinus for NIR light activated dual modal photodynamic and photothermal therapy in the second biological window. Adv Mat. 2014; 26: 6689-95.

94. Bugaj AM. Targeted photodynamic therapy--a promising strategy of tumor treatment. Photochem Photobiol Sci. 2011; 10: 1097-109.

95. Morton JG, Day ES, Halas NJ, West JL. Nanoshells for photothermal cancer therapy. Methods Mol Biol. 2010; 624: 101-17.

96. Gatenby RA, Gillies RJ. Why do cancers have high aerobic glycolysis? Nature Rev Cancer. 2004; 4: 891-9.

97. Allison RR, Mota HC, Bagnato VS, Sibata CH. Bio-nanotechnology and photodynamic therapy--state of the art review. Photodiagnosis Photodynamic Therapy. 2008; 5: 19-28.

98. Singh R, Lillard JW, Jr. Nanoparticle-based targeted drug delivery. Exper Mol Pathology. 2009; 86: 215-23.

99. Krasnici S, Werner A, Eichhorn ME, Schmitt-Sody M, Pahernik SA, Sauer B, et al. Effect of the surface charge of liposomes on their uptake by angiogenic tumor vessels. Int J Cancer. 2003; 105: 561-7.

100. Ichikawa K, Hikita T, Maeda N, Takeuchi Y, Namba Y, Oku N. PEGylation of liposome decreases the susceptibility of liposomal drug in cancer photodynamic therapy. Biol Pharm Bull. 2004; 27: 443-4. 
101. Harris JM, Chess RB. Effect of pegylation on pharmaceuticals. Nature Rev Drug Discov. 2003; 2: 214-21.

102. Pires P, Simoes S, Nir S, Gaspar R, Duzgunes N, Pedroso de Lima MC. Interaction of cationic liposomes and their DNA complexes with monocytic leukemia cells. Biochimica Biophysica Acta. 1999; 1418: 71-84.

103. Thurston G, McLean JW, Rizen M, Baluk P, Haskell A, Murphy TJ, et al. Cationic liposomes target angiogenic endothelial cells in tumors and chronic inflammation in mice. J Clin Invest. 1998; 101: 1401-13.

104. Synatschke CV, Nomoto T, Cabral H, Fortsch M, Toh K, Matsumoto Y, et al. Multicompartment micelles with adjustable poly(ethylene glycol) shell for efficient in vivo photodynamic therapy. ACS Nano. 2014; 8: 1161-72.

105. Peer D, Karp JM, Hong S, FaroKHzad OC, Margalit R, Langer R. Nanocarriers as an emerging platform for cancer therapy. Nat Nanotechnol. 2007; 2: 751-60.

106. Li Z, Wang C, Cheng L, Gong H, Yin S, Gong Q, et al. PEG-functionalized iron oxide nanoclusters loaded with chlorin e6 for targeted, NIR light induced, photodynamic therapy. Biomaterials. 2013; 34: 9160-70.

107. Sun Y, Chen ZL, Yang XX, Huang P, Zhou XP, Du XX. Magnetic chitosan nanoparticles as a drug delivery system for targeting photodynamic therapy. Nanotechnol. 2009; 20: 135102.

108. Wu M, Wang Q, Zhang D, Liao N, Wu L, Huang A, et al. Magnetite nanocluster@poly(dopamine)-PEG@ indocyanine green nanobead with magnetic field-targeting enhanced MR imaging and photothermal therapy in vivo. Colloids Surfaces B. 2016; 141: 467-75.

109. Pan UN, Khandelia R, Sanpui P, Das S, Paul A, Chattopadhyay A. Protein-Based Multifunctional Nanocarriers for Imaging, Photothermal Therapy and Anti-Cancer Drug Delivery. ACS Appl Mat Interfaces. 2016, in press. DOI: $10.1021 /$ acsami.6b06099.

110. Yu J, Yin W, Zheng $X$, Tian G, Zhang $X$, Bao T, et al. Smart MoS2/Fe3O4 Nanotheranostic for Magnetically Targeted Photothermal Therapy Guided by Magnetic Resonance/Photoacoustic Imaging. Theranostics. 2015; 5: 931-45.

111. Zhou Z, Sun Y, Shen J, Wei J, Yu C, Kong B, et al. Iron/iron oxide core/shell nanoparticles for magnetic targeting MRI and near-infrared photothermal therapy. Biomaterials. 2014; 35: 7470-8.

112. Fu G, Liu W, Li Y, Jin Y, Jiang L, Liang X, et al. Magnetic Prussian blue nanoparticles for targeted photothermal therapy under magnetic resonance imaging guidance. Bioconjugate Chem. 2014; 25: 1655-63.

113. Cheng L, Yang K, Li Y, Zeng X, Shao M, Lee ST, et al. Multifunctional nanoparticles for upconversion luminescence/MR multimodal imaging and magnetically targeted photothermal therapy. Biomaterials. 2012; 33: 2215-22.

114. Hou L, Yang X, Ren J, Wang Y, Zhang H, Feng Q, et al. A novel redox-sensitive system based on single-walled carbon nanotubes for chemo-photothermal therapy and magnetic resonance imaging. Int J Nanomed. 2016; 11: 607-24.

115. Li H, Song S, Wang W, Chen K. In vitro photodynamic therapy based on magnetic-luminescent Gd2O3:Yb,Er nanoparticles with bright three-photon up-conversion fluorescence under near-infrared light. Dalton transactions. 2015; 44: 16081-90

116. Yu J, Yang C, Li J, Ding Y, Zhang L, Yousaf MZ, et al. Multifunctional Fe5 C2 nanoparticles: a targeted theranostic platform for magnetic resonance imaging and photoacoustic tomography-guided photothermal therapy. Adv Mat. 2014; 26: 4114-20.

117. Yang K, Yang G, Chen L, Cheng L, Wang L, Ge C, et al. FeS nanoplates as a multifunctional nano-theranostic for magnetic resonance imaging guided photothermal therapy. Biomaterials. 2015; 38: 1-9.

118. Yang Y, Liu J, Liang C, Feng L, Fu T, Dong Z, et al. Nanoscale Metal-Organic Particles with Rapid Clearance for Magnetic Resonance Imaging-Guided Photothermal Therapy. ACS Nano. 2016; 10: 2774-81.

119. Iga $K$, Ogawa $Y$, Toguchi $H$. Heat-induced drug release rate and maximal targeting index of thermosensitive liposome in tumor-bearing mice. Pharm Res. 1992; 9: 658-62.

120. McDaniel JR, MacEwan SR, Li X, Radford DC, Landon CD, Dewhirst M, et al. Rational design of "heat seeking" drug loaded polypeptide nanoparticles that thermally target solid tumors. Nano Lett. 2014; 14: 2890-5.

121. Chen MC, Lin ZW, Ling MH. Near-Infrared Light-Activatable Microneedle System for Treating Superficial Tumors by Combination of Chemotherapy and Photothermal Therapy. ACS Nano. 2016; 10: 93-101.

122. Yoon I, Li JZ, Shim YK. Advance in photosensitizers and light delivery for photodynamic therapy. Clin Endoscopy. 2013; 46: 7-23.

123. Yue C, Zhang C, Alfranca G, Yang Y, Jiang X, Yang Y, et al. Near-Infrared Light Triggered ROS-activated Theranostic Platform based on Ce6-CPT-UCNPs for Simultaneous Fluorescence Imaging and Chemo-Photodynamic Combined Therapy. Theranostics. 2016; 6: 456-69.

124. Magalhaes CM, Esteves Da Silva JC, Pinto Da Silva L. Chemi/Bioluminescence as an Excitation Source in Photodynamic Therapy of Cancer: A Critical Review. Chemphyschem. 2016, in press. DOI: 10.1002/cphc. 201600270.

125. Kim YR, Kim S, Choi JW, Choi SY, Lee SH, Kim H, et al. Bioluminescence-activated deep-tissue photodynamic therapy of cancer. Theranostics. 2015; 5: 805-17.

126. Lajunen $\mathrm{T}$, Viitala $\mathrm{L}$, Kontturi $\mathrm{LS}$, Laaksonen $\mathrm{T}$, Liang $\mathrm{H}_{\text {, }}$ Vuorimaa-Laukkanen E, et al. Light induced cytosolic drug delivery from liposomes with gold nanoparticles. J Controlled Release. 2015; 203: 85-98.

127. Carter KA LD, Razi A, Geng J, Shao S, Ortega J, Lovell JF. Sphingomyelin Liposomes Containing Porphyrin-phospholipid for Irinotecan Chemophototherapy. Theranostics 2016; 6: 2329-36.
128. Luo D, Li N, Carter KA, Lin C, Geng J, Shao S, et al. Rapid Light-Triggered Drug Release in Liposomes Containing Small Amounts of Unsaturated and Porphyrin-Phospholipids. Small. 2016; 12: 3039-47.

129. Carter KA, Wang S, Geng J, Luo D, Shao S, Lovell JF. Metal Chelation Modulates Phototherapeutic Properties of Mitoxantrone-Loaded Porphyrin-Phospholipid Liposomes. Mol Pharm. 2016; 13: 420-7.

130. Miranda D, Lovell JF. Mechanisms of light-induced liposome permeabilization. Bioeng Translational Med. 2016, in press. DOI: 10.1002/btm2.10032.

131. Bertrand N, Wu J, Xu X, Kamaly N, Farokhzad OC. Cancer nanotechnology: The impact of passive and active targeting in the era of modern cancer biology. Adv Drug Deliv Rev. 2014; 66: 2-25.

132. Choi CHJ, Alabi CA, Webster P, Davis ME. Mechanism of active targeting in solid tumors with transferrin-containing gold nanoparticles. Proc Natl Acad Sci. 2010; 107: 1235-40.

133. Shen S, Tang H, Zhang X, Ren J, Pang Z, Wang D, et al. Targeting mesoporous silica-encapsulated gold nanorods for chemo-photothermal therapy with near-infrared radiation. Biomaterials. 2013; 34: 3150-8.

134. Li Z, Huang P, Zhang X, Lin J, Yang S, Liu B, et al. RGD-Conjugated Dendrimer-Modified Gold Nanorods for in Vivo Tumor Targeting and Photothermal Therapy. Mol Pharm. 2010; 7: 94-104.

135. Meyers JD, Cheng Y, Broome AM, Agnes RS, Schluchter MD, Margevicius S, et al. Peptide-Targeted Gold Nanoparticles for Photodynamic Therapy of Brain Cancer. Particle Particle Systems Character. 2015; 32: 448-57.

136. Conway CL, Walker I, Bell A, Roberts DJ, Brown SB, Vernon DI. In vivo and in vitro characterisation of a protoporphyrin IX-cyclic RGD peptide conjugate for use in photodynamic therapy. Photochem Photobiol Sci. 2008; 7: 290-8.

137. Van Driel PB, Boonstra MC, Slooter MD, Heukers R, Stammes MA, Snoeks TJ, et al. EGFR targeted nanobody-photosensitizer conjugates for photodynamic therapy in a pre-clinical model of head and neck cancer. J Controlled Release. 2016; 229: 93-105.

138. Xia L, Kong X, Liu X, Tu L, Zhang Y, Chang Y, et al. An upconversion nanoparticle-zinc phthalocyanine based nanophotosensitizer for photodynamic therapy. Biomaterials. 2014; 35: 4146-56.

139. Jin CS, Cui L, Wang F, Chen J, Zheng G. Targeting-triggered porphysome nanostructure disruption for activatable photodynamic therapy. Adv Healthcare Mat. 2014; 3: 1240-9.

140. Kotagiri N, Sudlow GP, Akers WJ, Achilefu S. Breaking the depth dependency of phototherapy with Cerenkov radiation and low-radiance-responsive nanophotosensitizers. Nat Nano. 2015; 10: 370-9.

141. Wang K, Zhang Y, Wang J, Yuan A, Sun M, Wu J, et al. Self-assembled IR780-loaded transferrin nanoparticles as an imaging, targeting and PDT/PTT agent for cancer therapy. Sci Rep. 2016; 6: 27421.

142. Shieh Y-A, Yang S-J, Wei M-F, Shieh M-J. Aptamer-Based Tumor-Targeted Drug Delivery for Photodynamic Therapy. ACS Nano. 2010; 4: 1433-42.

143. Yoon HY, Koo H, Choi KY, Lee SJ, Kim K, Kwon IC, et al. Tumor-targeting hyaluronic acid nanoparticles for photodynamic imaging and therapy. Biomaterials. 2012; 33: 3980-9.

144. Nicolas J, Mura S, Brambilla D, Mackiewicz N, Couvreur P. Design, functionalization strategies and biomedical applications of targeted biodegradable/biocompatible polymer-based nanocarriers for drug delivery. Chem Soc Rev. 2013; 42: 1147-235.

145. Wang AZ, Gu F, Zhang L, Chan JM, Radovic-Moreno A, Shaikh MR, et al. Biofunctionalized targeted nanoparticles for therapeutic applications. Expert Opin Biol Therapy. 2008; 8: 1063-70.

146. Ladner RC, Sato AK, Gorzelany J, de Souza M. Phage display-derived peptides as therapeutic alternatives to antibodies. Drug Discov Today. 2004; 9: 525-9.

147. Accardo A, Tesauro D, Morelli G. Peptide-based targeting strategies for simultaneous imaging and therapy with nanovectors. Polymer J. 2013; 45: 481-93.

148. Stefflova K, Li H, Chen J, Zheng G. Peptide-Based Pharmacomodulation of a Cancer-Targeted Optical Imaging and Photodynamic Therapy Agent. Bioconjugate Chem. 2007; 18: 379-88.

149. Charo IF, Nannizzi L, Smith JW, Cheresh DA. The vitronectin receptor alpha v beta 3 binds fibronectin and acts in concert with alpha 5 beta 1 in promoting cellular attachment and spreading on fibronectin. J Cell Biol. 1990; 111: 2795-800.

150. Zhen Z, Tang W, Chuang Y-J, Todd T, Zhang W, Lin X, et al. Tumor Vasculature Targeted Photodynamic Therapy for Enhanced Delivery of Nanoparticles. ACS Nano. 2014; 8: 6004-13.

151. Cheng S-H, Lee C-H, Chen M-C, Souris JS, Tseng F-G, Yang C-S, et al. Tri-functionalization of mesoporous silica nanoparticles for comprehensive cancer theranostics - the trio of imaging, targeting and therapy. J Mat Chem. 2010; 20: 6149-57.

152. Slowing II, Trewyn BG, Giri S, Lin VSY. Mesoporous Silica Nanoparticles for Drug Delivery and Biosensing Applications. Adv Func Mat. 2007; 17: 1225-36.

153. Zhou A, Wei Y, Wu B, Chen Q, Xing D. Pyropheophorbide A and c(RGDyK) Comodified Chitosan-Wrapped Upconversion Nanoparticle for Targeted Near-Infrared Photodynamic Therapy. Mol Pharm. 2012; 9: 1580-9.

154. Wang S, Lu W, Tovmachenko O, Rai US, Yu H, Ray PC. Challenge in understanding size and shape dependent toxicity of gold nanomaterials in human skin keratinocytes. Chem Physics Lett. 2008; 463: 145-9.

155. Hao Y, Zhang B, Zheng C, Ji R, Ren X, Guo F, et al. The tumor-targeting core-shell structured DTX-loaded PLGA@Au nanoparticles for 
chemo-photothermal therapy and X-ray imaging. J Controlled Release. 2015; 220(Part A): 545-55.

156. Patino T, Mahajan U, Palankar R, Medvedev N, Walowski J, Munzenberg M, et al. Multifunctional gold nanorods for selective plasmonic photothermal therapy in pancreatic cancer cells using ultra-short pulse near-infrared laser irradiation. Nanoscale. 2015; 7: 5328-37.

157. Patel LN, Zaro JL, Shen W-C. Cell Penetrating Peptides: Intracellular Pathways and Pharmaceutical Perspectives. Pharm Res. 2007; 24: 1977-92.

158. Choi Y, McCarthy JR, Weissleder R, Tung C-H. Conjugation of a Photosensitizer to an Oligoarginine-Based Cell-Penetrating Peptide Increases the Efficacy of Photodynamic Therapy. ChemMedChem. 2006; 1: 458-63.

159. Zhang R, Feng G, Zhang C-J, Cai X, Cheng X, Liu B. Real-Time Specific Light-Up Sensing of Transferrin Receptor: Image-Guided Photodynamic Ablation of Cancer Cells through Controlled Cytomembrane Disintegration. Anal Chem. 2016; 88: 4841-8.

160. Yuan H, Fales AM, Vo-Dinh T. TAT Peptide-Functionalized Gold Nanostars: Enhanced Intracellular Delivery and Efficient NIR Photothermal Therapy Using Ultralow Irradiance. J Am Chem Soc. 2012; 134: 11358-61.

161. Ichikawa K, Hikita T, Maeda N, Yonezawa S, Takeuchi Y, Asai T, et al. Antiangiogenic photodynamic therapy (PDT) by using long-circulating liposomes modified with peptide specific to angiogenic vessels. Biochim Biophys Acta. 2005; 1669: 69-74.

162. Wang J, Dong B, Chen B, Jiang Z, Song H. Selective photothermal therapy for breast cancer with targeting peptide modified gold nanorods. Dalton Transactions. 2012; 41: 11134-44.

163. Conde J, Oliva N, Zhang Y, Artzi N. Local triple-combination therapy results in tumour regression and prevents recurrence in a colon cancer model. Nat Mat. 2016; 15: 1128-38.

164. Narsireddy A, Vijayashree K, Adimoolam MG, Manorama SV, Rao NM. Photosensitizer and peptide-conjugated PAMAM dendrimer for targeted in vivo photodynamic therapy. Int I Nanomed. 2015; 10: 6865-78.

165. Mitsunaga M, Ogawa M, Kosaka N, Rosenblum LT, Choyke PL, Kobayashi H. Cancer cell-selective in vivo near infrared photoimmunotherapy targeting specific membrane molecules. Nat Med. 2011; 17: 1685-91.

166. Fabbrini M, Trachsel E, Soldani P, Bindi S, Alessi P, Bracci L, et al. Selective occlusion of tumor blood vessels by targeted delivery of an antibody-photosensitizer conjugate. Int J Cancer. 2006; 118: 1805-13.

167. Goff BA, Blake J, Bamberg MP, Hasan T. Treatment of ovarian cancer with photodynamic therapy and immunoconjugates in a murine ovarian cancer model. Br J Cancer. 1996; 74: 1194-8.

168. Spring BQ, Abu-Yousif AO, Palanisami A, Rizvi I, Zheng X, Mai Z, et al. Selective treatment and monitoring of disseminated cancer micrometastases in vivo using dual-function, activatable immunoconjugates. Proc Natl Acad Sci. 2014; 111: E933-E42.

169. Schrama D, Reisfeld RA, Becker JC. Antibody targeted drugs as cancer therapeutics. Nature Rev Drug discovery. 2006; 5: 147-59.

170. Pietras RJ, Pegram MD, Finn RS, Maneval DA, Slamon DJ. Remission of human breast cancer xenografts on therapy with humanized monoclonal antibody to HER-2 receptor and DNA-reactive drugs. Oncogene. 1998; 17: 2235-49.

171. Van de Broek B, Devoogdt N, D'Hollander A, Gijs H-L, Jans K, Lagae L, et al. Specific cell targeting with nanobody conjugated branched gold nanoparticles for photothermal therapy. ACS Nano. 2011; 5: 4319-28.

172. El-Sayed IH, Huang XH, El-Sayed MA. Selective laser photo-thermal therapy of epithelial carcinoma using anti-EGFR antibody conjugated gold nanoparticles. Cancer Lett. 2006; 239: 129-35.

173. Kim J, Park S, Lee JE, Jin SM, Lee JH, Lee IS, et al. Designed Fabrication of Multifunctional Magnetic Gold Nanoshells and Their Application to Magnetic Resonance Imaging and Photothermal Therapy. Angewandte Chem Int Ed. 2006; 118: 7918-22.

174. El-Sayed IH, Huang X, El-Sayed MA. Selective laser photo-thermal therapy of epithelial carcinoma using anti-EGFR antibody conjugated gold nanoparticles. Cancer Lett. 2006; 239: 129-35.

175. Ji X, Shao R, Elliott AM, Stafford RJ, Esparza-Coss E, Bankson JA, et al. Bifunctional Gold Nanoshells with a Superparamagnetic Iron Oxide-Silica Core Suitable for Both MR Imaging and Photothermal Therapy. J Phys Chem C. 2007; 111: 6245-51.

176. Millenbaugh NJ, Baskin JB, DeSilva MN, Elliott WR, Glickman RD. Photothermal killing of Staphylococcus aureus using antibody-targeted gold nanoparticles. Int J Nanomedicine. 2015; 10: 1953-60.

177. Qian ZM, Li H, Sun H, Ho K. Targeted Drug Delivery via the Transferrin Receptor-Mediated Endocytosis Pathway. Pharmacological Rev. 2002; 54: 561-87.

178. Daniels TR, Bernabeu E, Rodríguez JA, Patel S, Kozman M, Chiappetta DA, et al. The transferrin receptor and the targeted delivery of therapeutic agents against cancer. Biochim Biophys Acta. 2012; 1820: 291-317.

179. Daniels TR, Delgado T, Rodriguez JA, Helguera G, Penichet ML. The transferrin receptor part I: Biology and targeting with cytotoxic antibodies for the treatment of cancer. Clin Immunol. 2006; 121: 144-58.

180. Yu J, Hsu C-H, Huang C-C, Chang P-Y. Development of Therapeutic Au-Methylene Blue Nanoparticles for Targeted Photodynamic Therapy of Cervical Cancer Cells. ACS Appl Mat Interfaces. 2014; 7: 432-41.

181. Derycke AS, Kamuhabwa A, Gijsens A, Roskams T, De Vos D, Kasran A, et al. Transferrin-conjugated liposome targeting of photosensitizer AIPCS4 to rat bladder carcinoma cells. I National Cancer Inst. 2004; 96: 1620-30.
182. Li JL, Day D, Gu M. Ultra-Low Energy Threshold for Cancer Photothermal Therapy Using Transferrin-Conjugated Gold Nanorods. Adv Mat. 2008; 20: 3866-71.

183. Li J-L, Wang L, Liu X-Y, Zhang Z-P, Guo H-C, Liu W-M, et al. In vitro cancer cell imaging and therapy using transferrin-conjugated gold nanoparticles. Cancer Lett. 2009; 274: 319-26.

184. Marotta DE, Cao W, Wileyto EP, Li H, Corbin I, Rickter E, et al. Evaluation of bacteriochlorophyll-reconstituted low-density lipoprotein nanoparticles for photodynamic therapy efficacy in vivo. Nanomedicine (Lond). 2011; 6: 475-87.

185. Misawa J, Moriwaki S, Kohno E, Hirano T, Tokura Y, Takigawa M. The role of low-density lipoprotein receptors in sensitivity to killing by Photofrin-mediated photodynamic therapy in cultured human tumor cell lines. J Dermatological Sci. 2005; 40: 59-61.

186. Li H, Marotta DE, Kim S, Busch TM, Wileyto EP, Zheng G. High payload delivery of optical imaging and photodynamic therapy agents to tumors using phthalocyanine-reconstituted low-density lipoprotein nanoparticles. J Biomed Optics. 2005; 10: 41203.

187. Luiza Andreazza N, Vevert-Bizet C, Bourg-Heckly G, Sureau F, Jose Salvador $\mathrm{M}$, Bonneau S. Berberine as a photosensitizing agent for antitumoral photodynamic therapy: Insights into its association to low density lipoproteins. Int J Pharm. 2016; 510: 240-9.

188. Wozniak M, Dus-Szachniewicz K, Ziolkowski P. Insulin-Like Growth Factor-2 Is Induced Following 5-Aminolevulinic Acid-Mediated Photodynamic Therapy in SW620 Human Colon Cancer Cell Line. Int J Mol Sci. 2015; 16: 23615-29.

189. Xu D, Chen X, Chen K, Peng Y, Li Y, Ke Y, et al. Tetra-sulfonate phthalocyanine zinc-bovine serum albumin conjugate-mediated photodynamic therapy of human glioma. J Biomaterials Appl. 2014; 29: 378-85.

190. Hamblin MR, Miller JL, Ortel B. Scavenger-receptor targeted photodynamic therapy. Photochem Photobiol. 2000; 72: 533-40.

191. Liu Q, Hamblin MR. Macrophage-targeted photodynamic therapy: scavenger receptor expression and activation state. Int J Immunopathol Pharmacol. 2005; 18: 391-402.

192. Chang JE, Yoon IS, Sun PL, Yi E, Jheon S, Shim CK. Anticancer efficacy of photodynamic therapy with hematoporphyrin-modified, doxorubicin-loaded nanoparticles in liver cancer. J Photochem Photobiol B. 2014; 140: 49-56.

193. Zhang B, Wang H, Shen S, She X, Shi W, Chen J, et al. Fibrin-targeting peptide CREKA-conjugated multi-walled carbon nanotubes for self-amplified photothermal therapy of tumor. Biomaterials. 2016; 79: 46-55.

194. Farokhzad OC, Karp JM, Langer R. Nanoparticle-aptamer bioconjugates for cancer targeting. Expert Opin Drug Deliv. 2006; 3: 311-24.

195. Dua P, Kim S, Lee D-k. Nucleic acid aptamers targeting cell-surface proteins. Methods. 2011; 54: 215-25.

196. Pestourie C, Tavitian B, Duconge F. Aptamers against extracellular targets for in vivo applications. Biochimie. 2005; 87: 921-30

197. Wang J, Zhu G, You M, Song E, Shukoor MI, Zhang K, et al. Assembly of Aptamer Switch Probes and Photosensitizer on Gold Nanorods for Targeted Photothermal and Photodynamic Cancer Therapy. ACS Nano. 2012; 6: 5070-7.

198. Huang Y-F, Sefah K, Bamrungsap S, Chang H-T, Tan W. Selective Photothermal Therapy for Mixed Cancer Cells Using Aptamer-Conjugated Nanorods. Langmuir. 2008; 24: 11860-5.

199. Ocsoy I, Isiklan N, Cansiz S, Özdemir N, Tan W. ICG-Conjugated magnetic graphene oxide for dual photothermal and photodynamic therapy. RSC Advances. 2016; 6: 30285-92.

200. Low PS, Kularatne SA. Folate-targeted therapeutic and imaging agents for cancer. Current Opin Chem Biol. 2009; 13: 256-62.

201. Wang H, Zheng L, Peng C, Shen M, Shi X, Zhang G. Folic acid-modified dendrimer-entrapped gold nanoparticles as nanoprobes for targeted CT imaging of human lung adencarcinoma. Biomaterials. 2013; 34: 470-80.

202. Low PS, Henne WA, Doorneweerd DD. Discovery and Development of Folic-Acid-Based Receptor Targeting for Imaging and Therapy of Cancer and Inflammatory Diseases. Accounts Chem Res. 2008; 41: 120-9.

203. Huang P, Xu C, Lin J, Wang C, Wang X, Zhang C, et al. Folic acid-conjugated graphene oxide loaded with photosensitizers for targeting photodynamic therapy. Theranostics. 2011; 1: 240-50.

204. Huang P, Bao L, Zhang C, Lin J, Luo T, Yang D, et al. Folic acid-conjugated Silica-modified gold nanorods for X-ray/CT imaging-guided dual-mode radiation and photo-thermal therapy. Biomaterials. 2011; 32: 9796-809.

205. Xia H-X, Yang X-Q, Song J-T, Chen J, Zhang M-Z, Yan D-M, et al. Folic acid-conjugated silica-coated gold nanorods and quantum dots for dual-modality CT and fluorescence imaging and photothermal therapy. J Mat Chem B. 2014; 2: 1945-53.

206. Ryu T-K, Baek SW, Kang RH, Choi S-W. Selective Photothermal Tumor Therapy Using Nanodiamond-Based Nanoclusters with Folic Acid. Adv Functional Mat. 2016; 26: 6428-36.

207. Zhang Z, Blessington D, Li H, Busch TM, Glickson J, Luo O, et al. Redox ratio of mitochondria as an indicator for the response of photodynamic therapy. $J$ Biomed optics. 2004; 9: 772-8.

208. Zhang M, Zhang Z, Blessington D, Li H, Busch TM, Madrak V, et al. Pyropheophorbide 2-deoxyglucosamide: a new photosensitizer targeting glucose transporters. Bioconjugate Chem. 2003; 14: 709-14.

209. Li G, Pandey SK, Graham A, Dobhal MP, Mehta R, Chen Y, et al. Functionalization of OEP-Based Benzochlorins To Develop Carbohydrate-Conjugated Photosensitizers. Attempt To Target $\beta$-Galactoside-Recognized Proteins. J Org Chem. 2004; 69: 158-72. 
210. Zheng G, Graham A, Shibata M, Missert JR, Oseroff AR, Dougherty TJ, et al. Synthesis of $\beta$-Galactose-Conjugated Chlorins Derived by Enyne Metathesis as Galectin-Specific Photosensitizers for Photodynamic Therapy. J Org Chem. 2001; 66: 8709-16.

211. Achelle S, Couleaud P, Baldeck P, Teulade-Fichou M-P, Maillard P. Carbohydrate-Porphyrin Conjugates with Two-Photon Absorption Properties as Potential Photosensitizing Agents for Photodynamic Therapy. Eur J Org Chem. 2011; 2011: 1271-9.

212. Huang P, Lin J, Li W, Rong P, Wang Z, Wang S, et al. Biodegradable gold nanovesicles with ultra-strong plasmonic coupling effect for photoacoustic imaging and photothermal therapy. Angewandte Chem Int Ed. 2013; 52: 13958-64.

213. Huang X, El-Sayed IH, Qian W, El-Sayed MA. Cancer Cell Imaging and Photothermal Therapy in the Near-Infrared Region by Using Gold Nanorods. J Am Chem Soc. 2006; 128: 2115-20.

214. Guo M, Mao H, Li Y, Zhu A, He H, Yang H, et al. Dual imaging-guided photothermal/photodynamic therapy using micelles. Biomaterials. 2014; 35: 4656-66.

215. Chitgupi U, Zhang Y, Lo CY, Shao S, Song W, Geng J, et al. Sulfonated Polyethylenimine for Photosensitizer Conjugation and Targeting. Bioconjugate Chem. 2015; 26: 1633-9.

216. Chen Q, Wang C, Cheng L, He W, Cheng Z, Liu Z. Protein modified upconversion nanoparticles for imaging-guided combined photothermal and photodynamic therapy. Biomaterials. 2014; 35: 2915-23.

217. Entwistle J, Hall CL, Turley EA. HA receptors: Regulators of signalling to the cytoskeleton. J Cell Biochem. 1996; 61: 569-77.

218. Choi KY, Min KH, Na JH, Choi K, Kim K, Park JH, et al. Self-assembled hyaluronic acid nanoparticles as a potential drug carrier for cancer therapy: synthesis, characterization, and in vivo biodistribution. J Mat Chem. 2009; 19: 4102-7.

219. Li W, Zheng C, Pan Z, Chen C, Hu D, Gao G, et al. Smart hyaluronidase-actived theranostic micelles for dual-modal imaging guided photodynamic therapy. Biomaterials. 2016; 101: 10-9.

220. Cai Y, Tang Q, Wu X, Si W, Huang W, Zhang Q, et al. Diketopyrrolopyrrole Derivatives Grafting Hyaluronic Acid for Targeted Photodynamic Therapy. ChemistrySelect. 2016; 1: 3071-4.

221. Li F, Park S-J, Ling D, Park W, Han JY, Na K, et al. Hyaluronic acid-conjugated graphene oxide/photosensitizer nanohybrids for cancer targeted photodynamic therapy. J Mat Chem B. 2013; 1: 1678-86.

222. Yuan Y, Zhang CJ, Kwok RT, Xu S, Zhang R, Wu J, et al. Light-Up Probe for Targeted and Activatable Photodynamic Therapy with Real-Time In Situ Reporting of Sensitizer Activation and Therapeutic Responses. Adv Func Mater. 2015; 25: 6586-95.

223. Zhang Y, Deng C, Liu S, Wu J, Chen Z, Li C, et al. Active targeting of tumors through conformational epitope imprinting. Angewandte Chem Int Ed. 2015; 54: 5157-60.

224. Zhen Z, Tang W, Zhang W, Xie J. Folic acid conjugated ferritins as photosensitizer carriers for photodynamic therapy. Nanoscale. 2015; $7: 10330-3$.

225. Feng X, Zhang S, Wu H, Lou X. A novel folic acid-conjugated TiO2-SiO2 photosensitizer for cancer targeting in photodynamic therapy. Colloids Surfaces B. $2015 ; 125$ : 197-205.

226. Patel K, Raj BS, Chen Y, Lou X. Novel folic acid conjugated Fe 3 O 4-ZnO hybrid nanoparticles for targeted photodynamic therapy. Colloids Surfaces B. 2016; DOI: 10.1016/j.colsurfb.2016.10.045

227. Zhang C, Li C, Liu Y, Zhang J, Bao C, Liang S, et al. Gold Nanoclusters-Based Nanoprobes for Simultaneous Fluorescence Imaging and Targeted Photodynamic Therapy with Superior Penetration and Retention Behavior in Tumors. Adv Functional Mat. 2015; 25: 1314-25.

228. Choi Y, Kim S, Choi MH, Ryoo SR, Park J, Min DH, et al. Highly biocompatible carbon nanodots for simultaneous bioimaging and targeted photodynamic therapy in vitro and in vivo. Adv Functional Mat. 2014; 24: 5781-9.

229. Zeng L, Luo L, Pan $Y$, Luo S, Lu G, Wu A. In vivo targeted magnetic resonance imaging and visualized photodynamic therapy in deep-tissue cancers using folic acid-functionalized superparamagnetic-upconversion nanocomposites. Nanoscale. 2015; 7: 8946-54.

230. Wang X, Wang C, Cheng L, Lee S-T, Liu Z. Noble metal coated single-walled carbon nanotubes for applications in surface enhanced Raman scattering imaging and photothermal therapy. J Am Chem Soc. 2012; 134: 7414-22.

231. Wang D-W, Zhu X-M, Lee S-F, Chan H-M, Li H-W, Kong SK, et al. Folate-conjugated Fe 3O4@SiO 2@ gold nanorods@ mesoporous SiO 2 hybrid nanomaterial: a theranostic agent for magnetic resonance imaging and photothermal therapy. J Mat Chem B. 2013; 1: 2934-42 